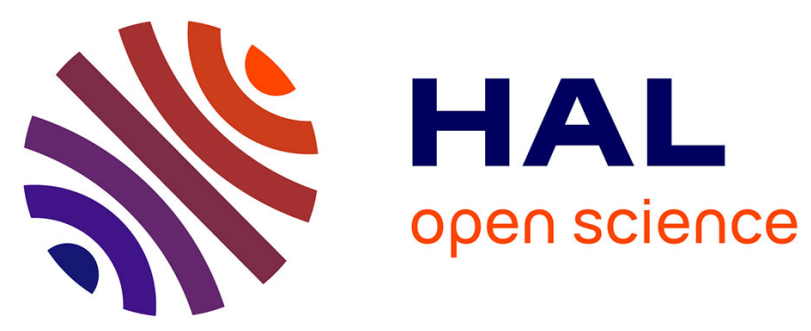

\title{
Residual stiffness and strength of shear connectors in steel-concrete composite beams after being subjected to a pull-out pre-damaging: An experimental investigation
} Piseth Heng, Mihai Bud, Hugues Somja, Mohammed Hjiaj, Jean-Marc Battini

\section{- To cite this version:}

Piseth Heng, Mihai Bud, Hugues Somja, Mohammed Hjiaj, Jean-Marc Battini. Residual stiffness and strength of shear connectors in steel-concrete composite beams after being subjected to a pull-out pre-damaging: An experimental investigation. Structures, 2017, 11, pp.189-205. 10.1016/j.istruc.2017.05.003 . hal-01616204

HAL Id: hal-01616204

https://hal-univ-rennes1.archives-ouvertes.fr/hal-01616204

Submitted on 13 Oct 2017

HAL is a multi-disciplinary open access archive for the deposit and dissemination of scientific research documents, whether they are published or not. The documents may come from teaching and research institutions in France or abroad, or from public or private research centers.
L'archive ouverte pluridisciplinaire $\mathbf{H A L}$, est destinée au dépôt et à la diffusion de documents scientifiques de niveau recherche, publiés ou non, émanant des établissements d'enseignement et de recherche français ou étrangers, des laboratoires publics ou privés. 


\section{Accepted Manuscript}

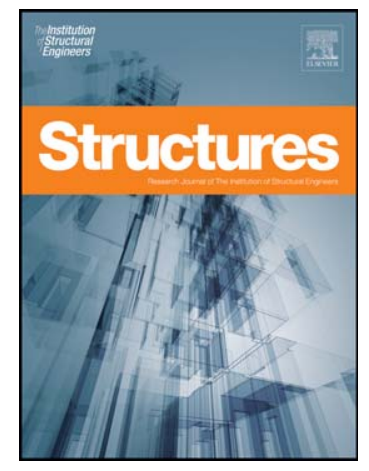

Residual Stiffness and Strength of Shear Connectors in Steel-Concrete Composite Beams after Being Submitted to a Pull-out Pre-damaging: An Experimental Investigation

Piseth Heng, Mihai Bud, Hugues Somja, Mohammed Hjiaj, Jean-Marc Battini

S2352-0124(17)30030-9

DOI: $\quad$ doi: $10.1016 /$ j.istruc.2017.05.003

Reference: $\quad$ ISTRUC 194

To appear in:

Received date: 29 July 2016

Revised date: $\quad 26$ April 2017

Accepted date: 21 May 2017

Please cite this article as: Heng Piseth, Bud Mihai, Somja Hugues, Hjiaj Mohammed, Battini Jean-Marc, Residual Stiffness and Strength of Shear Connectors in Steel-Concrete Composite Beams after Being Submitted to a Pull-out Pre-damaging: An Experimental Investigation, (2017), doi: 10.1016/j.istruc.2017.05.003

This is a PDF file of an unedited manuscript that has been accepted for publication. As a service to our customers we are providing this early version of the manuscript. The manuscript will undergo copyediting, typesetting, and review of the resulting proof before it is published in its final form. Please note that during the production process errors may be discovered which could affect the content, and all legal disclaimers that apply to the journal pertain. 


\title{
Residual Stiffness and Strength of Shear Connectors in Steel-Concrete Composite Beams after Being Submitted to a Pull-out Pre-damaging: An Experimental Investigation
}

\author{
Piseth Heng,a, Mihai Bud ${ }^{\mathrm{a}}$, Hugues Somja ${ }^{\mathrm{a}}$, Mohammed Hjiaja,*, Jean-Marc Battini ${ }^{\mathrm{b}}$ \\ ${ }^{a}$ INSA de Rennes, LGCGM/Structural Engineering Research Group, Université Européenne de Bretagne, \\ 20 avenue des Buttes de Coësmes, CS 70839, 35708 Rennes Cedex 7, France \\ ${ }^{b}$ Department of Civil and Architectural Engineering, KTH, Royal Institute of Technology, SE-10044 \\ Stockholm, Sweden
}

\begin{abstract}
Horizontal stability of the medium rise steel frame structures is usually ensured by vertical bracings and diaphragm action of composite floors. Load transfer within the composite floor system is made through shear connectors, e.g. headed studs. In an event of explosion, such connectors must reserve sufficient residual stiffness and strength in order to avoid a sudden or delayed collapse of the building. These remaining capacities have not been experimentally studied yet in the literature. This paper presents large scale horizontal push out tests to determine the residual stiffness of the shear connectors after being initially damaged by explosion. The initial damaging is reproduced by a pull-out test using a quasi-static loading. Two types of numerical simulation have also been developed using ABAQUS/CAE software to provide a better understanding of the experimental results.
\end{abstract}

Keywords: Explosion; shear stud; push-out; pullout; residual strength; composite floor; profile steel sheet

\section{Introduction}

The present-day serviceability of steel frame buildings in industry and commerce has exposed the structures with high risk to extreme and accidental loadings, particularly explosion. Many incidents, such as Azote de France Fertilizer factory in Toulouse (AFT),

\footnotetext{
*Corresponding author.

Email address: mohammed.hjiaj@insa-rennes.fr ( Mohammed Hjiaj)
} 
Buncefield in UK and CPR Tank Farm in Puerto Rico to name a few, have damaged structures within a large surrounding area, causing serious casualties and substantial property loss. It is thus increasingly important to design structural buildings with such exposure to withstand the effects of blast loading. The Buncefield investigation led to the recommendations on land use planning and the control of societal risk around major hazard sites in addition to Health and Safety Executive (HSE) to take into account not only direct human harm but also property damage and other harms to communities. Coming after the incident of AFT in Toulouse, a regulation was established to allow the design of concrete buildings that can resist blast actions with an intensity up to $12 \mathrm{kPa}$. However, steel framed buildings are not permitted to tolerate even with low level of explosion except if the spacing between steel frames is less than $5 \mathrm{~m}$. This consideration is based on inertia effects while robustness of steel structures, i.e. high ductility and redundancy, is not considered. Until recently, either large-scale buildings or concrete structures are included in the regulations while low-to-medium rise steel buildings subject to global explosion have not been studied yet. Consequently, a European project called Blast Actions on Structures In Steel (BASIS) has been proposed to investigate and develop a methodology for the safe design of low to medium rise office buildings subjected to large external explosions.

The research work in BASIS project is based on a reference building of a typical business park office building that fits the description of low to medium rise building. This threestorey office structure (See Fig. 1 and 2) was designed based on usual loadings in simple construction using the principle of Eurocodes 1993 and 1994. In this type of frame building, the composite floors are supported by steel columns. The wind actions are transmitted from façades to the vertical steel bracings by the diaphragm action of the composite floor and by shear actions of shear connection. From the reference building design in [1], the wind action expected to transmit through the shear connectors was estimated at $10 \mathrm{kN} / \mathrm{m}$. The response of such multi-storey steel frame building subjected to blast loading involves complex interactions between building envelope, composite floor, frame system, and connections. The load transfer between the composite floor and its frames depends strongly on the performance of the shear connectors. Headed steel stud anchors welded to steel beam and encased in 


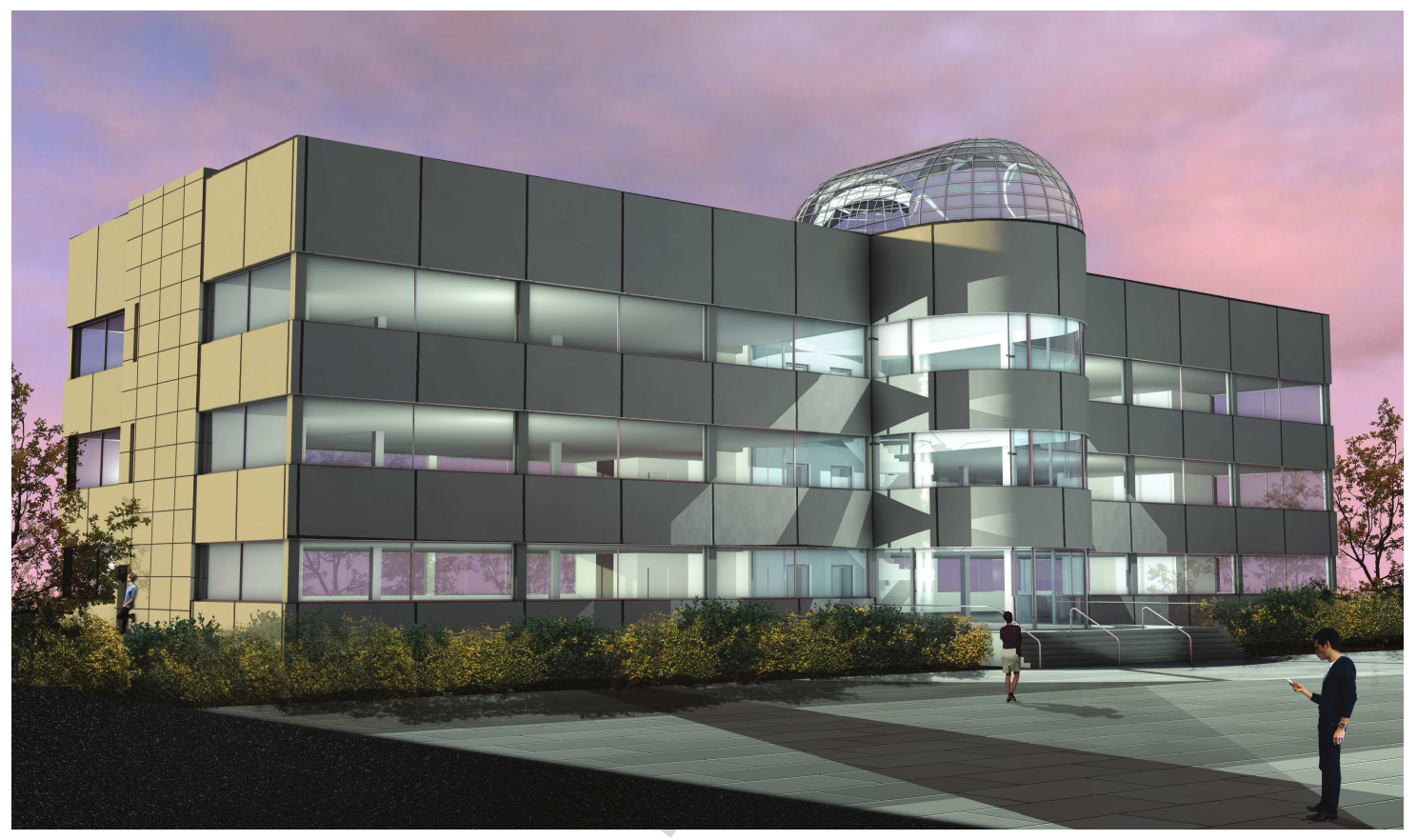

Figure 1: Architectural façade view

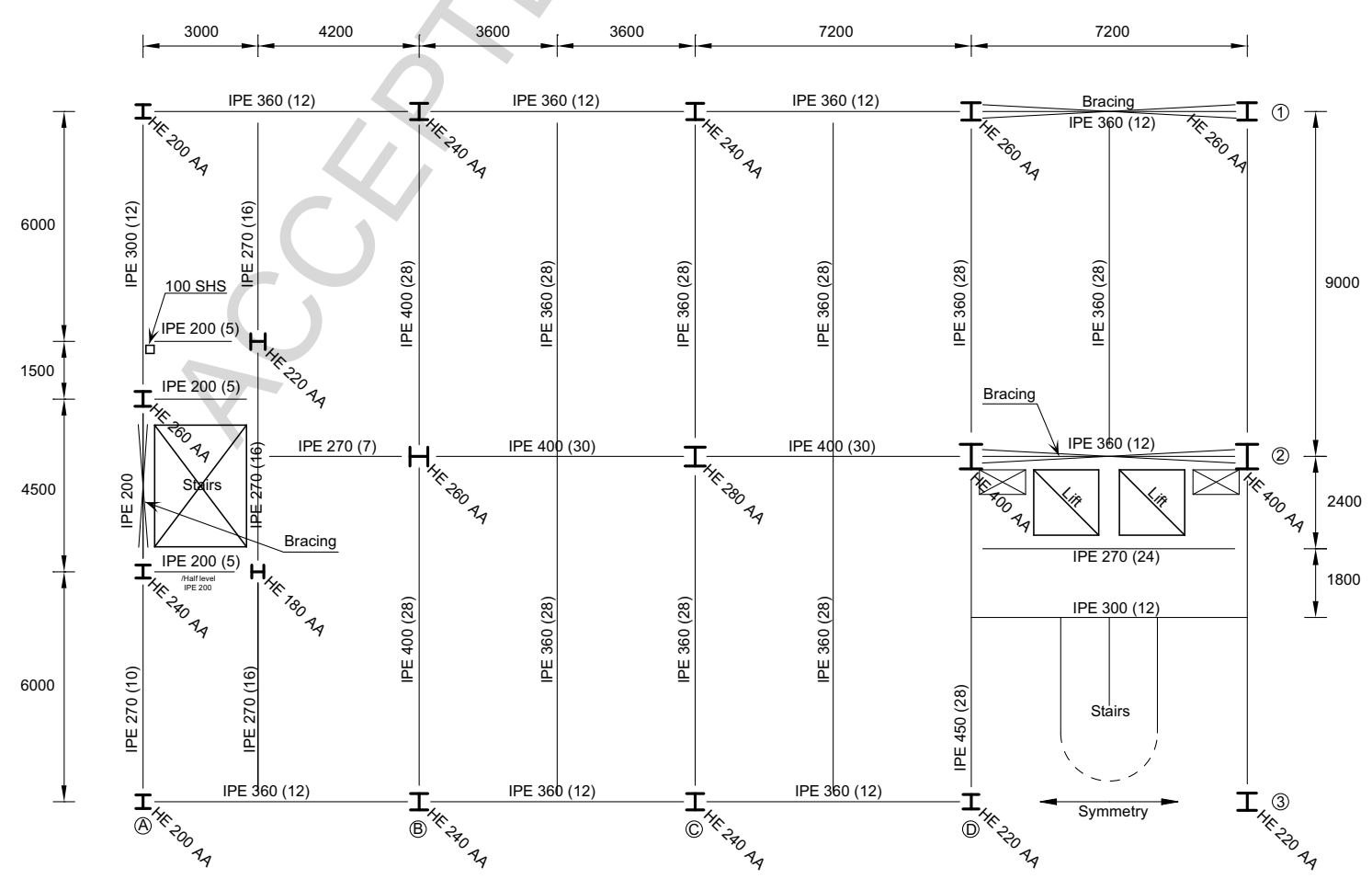

Figure 2: Level 1 and 2, office areas 
concrete are commonly used as shear connectors to transfer forces in the composite beam system. Being a part of BASIS project, this paper presents an experimental investigation on the residual shear stiffness and strength of stud connectors after being submitted to blast actions. For the past 50 years, different aspects of the behavior of the headed steel studs such as failure mode, shear capacity and load-slip relation have been assessed throughout empirical studies using small-scale standard or full scale push-out tests. After the earlier push-out tests [2, 3], small-scale standard tests were established in CP117 [4], BS5950 [5] and Eurocode 4 [6]. In such tests, the push-out specimen is composed of a profiled steel beam connected to two blocks of concrete by shear connectors. Ollgaard et al in 1971 [7] used the small scale push-out test setup to investigate the capacity and behavior of stud shear connectors embedded in lightweight and normal weight concrete. Prakash et al [8] presented modified pushout tests to determine shear strength and stiffness of high strength steel studs, in which the reinforcement, method of casting concrete and test setup were altered from the standard tests with an adaptation to enhance splitting resistance of reinforced concrete. In addition to this, Shim et al [9] performed pushout tests on specimens fabricated in accordance with Eurocode 4 [6] to determine static behavior of large stud shear connectors (diameter 25, 27, $30 \mathrm{~mm}$ stud). On the other hand, Lloyd and Wright [10] conducted a series of large scale push-out tests of composite beam specimens (See Fig. 3) with the objective to recommend a standard configuration for through-deck push-out test. In their study, 42 push-out tests have been performed by varying some parameters such as the width of the slab, the detail of mesh reinforcement, and the number of profiled steel sheet pitches. Having similar test setup to the one described in [10], Smith and Couchman [11] carried out 27 push tests on specimens of composite beam using a new push rig to investigate the effect of variables such as meshed position, transverse spacing of shear connectors, number of shear connectors per trough and the slab depth. In 2009, Hicks [12] also implemented two types of tests on the headed stud connectors welded in profiled steel sheeting and embedded in reinforced concrete slab. One of his setups is a standard push-out test as defined in Eurocode 4 [6] whereas the other setup is a full-scale composite beam illustrated in Fig. 4. Apart from this, Lam [13] proposed a new horizontal push-out test setup using full-scale specimens of composite beams with 
precast hollowcore slab. He performed 7 push-out tests with a new configuration of headed studs in solid RC slabs to validate the test procedure, and the results agreed well with the ones specified in the available codes $[5,6]$. This new full-scale horizontal test arrangement is proposed due to the reasons that the standard push-out test specified in Eurocode 4 does not fit for a specimen of precast hollowcore composite slab. Later in 2011, Qureshi et al [14] adopted the new horizontal push-out test configuration presented by Lam [13] to carry the push tests on headed shear studs in composite beams with composite profiled sheeting slab. Parametric studies were then performed through a simulation of the push-out test using a 3-dimentional nonlinear finite element model in ABAQUS/Explicit [15] to investigate the effect of shear connector spacing and layout on the shear connector capacity.

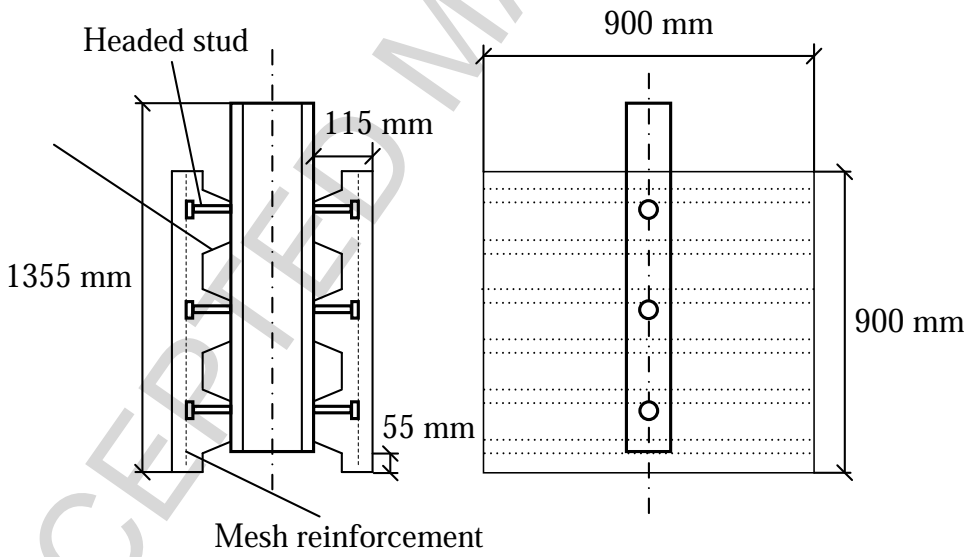

Figure 3: Lloyd and Wright's push test arrangement series A

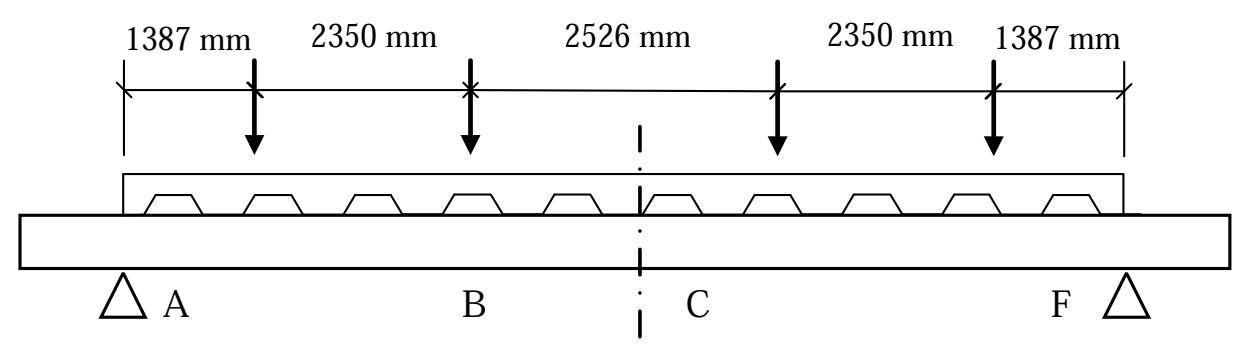

Figure 4: Hicks' composite beam 1 test arrangement

In composite construction of steel frame buildings, composite floors have important roles 
in performing diaphragm action both to transmit lateral loads to the bracing system and to pass on vertical load to frame system. In such a case, the headed shear studs are subjected to combined tension and shear action. Pallarés and Hajjar [16] assessed the limit state formulas for headed stud anchors under shear-tension interaction action against 54 experiments found in literatures $[17,18]$ in the context of AISC specifications and compared the results with standard provisions [19, 20, 21]. However, the structural behavior of headed shear studs embedded in composite slabs with profiled steel sheeting under combined action has not been assessed yet. Besides, to the best knowledge of the authors, the influence of the initial damage of the composite beam-slab connection caused by uplift blast action onto shear capacity of headed shear stud connectors has not been investigated in the literature yet. However, the knowledge of this residual strength is important for the design since the load bearing capacities of the composite beam rely on the composite action between the steel beam and the composite slab.

This paper aims at evaluating the influence of explosion on the shear capacity of headed shear stud connectors welded to steel beam and embedded in composite floor with profiled steel sheeting. A large-scale horizontal push-out test of the composite beam is employed to determine both initial and residual shear properties of the headed shear connectors. The initial damage caused by the explosion is experimentally reproduced by a pull-out test of the composite beam specimen. Two types of numerical simulations of the composite beam specimen, namely a simple beam model and a full solid element, have been created in ABAQUS/CAE [22] to validate and analyze the phenomenon in the experimental test.

\section{Experimental Plan}

To be able to determine experimentally the residual stiffness of the shear connectors in the composite beam after it has suffered out-of-plan damage caused by high pressure from blast, the following experimental plan was defined. First, three composite beam specimens were submitted to push-out tests at Institut National des Sciences Appliquées de Rennes (INSA de Rennes) in order to find their initial shear characteristics. Next, two of the specimens were sent to Institut National de l'Environnement Industriel et des Risques (INERIS) for 
the explosion test to generate damage due to blast. The third specimen was prepared to serve as a reference to define the shear capacities of the connectors without initial blast damage. After being exposed to explosion, the two specimen were delivered back to INSA de Rennes to perform the push-out tests in order to determine the residual shear stiffness and the ultimate shear resistance of the specimen. At this stage, the third specimen was also tested for the shear resistance.

Unfortunately, the explosion tests at INERIS had completely destroyed the two composite specimens, which made it impossible to test them for residual stiffness. As a consequence, it was decided to alter the experimental plan. A supplementary pull-out test was performed on the third specimen to quasi-statically reproduce the pre-damaging of the specimen. It has been proven in [23] that the response of the specimen under explosion in the experiment was quasi-static. Such behaviour can be reproduced by the pull-out type test. The damaged specimen was then tested for the residual stiffness and the ultimate shear resistance.

\section{Specimen and Material Properties}

The composite beam specimen was defined with regard to the aforementioned reference building, with some necessary adaptations following the installation capacities of the laboratory at INERIS. Illustrated in Fig. 5, the specimen was composed of a composite floor with steel profile sheet, an IPE-200 steel beam made of S355 steel and a line of 8 shear studs with a nominal yield strength of $450 \mathrm{MPa}$. The composite floor, with the dimension of $1800 \mathrm{~mm}-$ by-2000mm and the thickness of $100 \mathrm{~mm}$, was fabricated by casting concrete of a C25/30 type on a corrugated steel sheeting Comflor 46 whose nominal yield limit was $280 \mathrm{MPa}$ (supplied by Tata Steel) with HA-6mm meshed reinforcement. A 20-mm concrete cover was chosen in order to have the same amount of concrete over and under the rebar mesh above the crest of the steel sheet. The spacing of reinforcement was arranged to be $225 \mathrm{~mm}$ in both directions. In each flute, an HA-8mm rebar was placed as prescribed in the technical documentation of the Comflor. As the flute at the edges were changed to respect the width of the tunnel used to apply the blast action, a supplementary reinforcement was added to obtain the same steel-concrete ratio. In the other direction, the reinforcement was 
adapted at the edges because the length of the specimen was also fixed by the dimension of the blast setup. Consequently, for edges perpendicular to crest lines, two HA-6mm rebars with spacing of $75 \mathrm{~mm}$ were welded to 6 - $\mathrm{mm}$ rebar mesh, see Fig. 5. For edges parallel to crest lines, the rebar frame in the edge flutes consisted of four HA-6mm rebars placed along the edges. The lower rebars were fixed to the rebar mesh by stirrup of 6- $m m$ diameter with 75-mm spacing. Similarly, in each flute, two HA-6mm rebars were welded to both the lower 8-mm rebar along the crest line and the two HA- $6 \mathrm{~mm}$ rebars. The rebars of diameter 6 $\mathrm{mm}$ and $8 \mathrm{~mm}$ had a nominal yield strength of $500 \mathrm{MPa}$. In order to know the actual yield strength, six tensile coupon tests were made for each material, i.e. Comflor 46, 8-mm rebar, 6-mm rebar and shear stud. The results are summarized in Table 1 where the yield strength, the mean value of yield strength, the ultimate strength and the mean value of the ultimate strength are denoted by $f_{y}, f_{y m}, f_{u}$ and $f_{u m}$, respectively. For all the materials, the obtained mean values passed the nominal yield strength. On the other hand, the concrete material

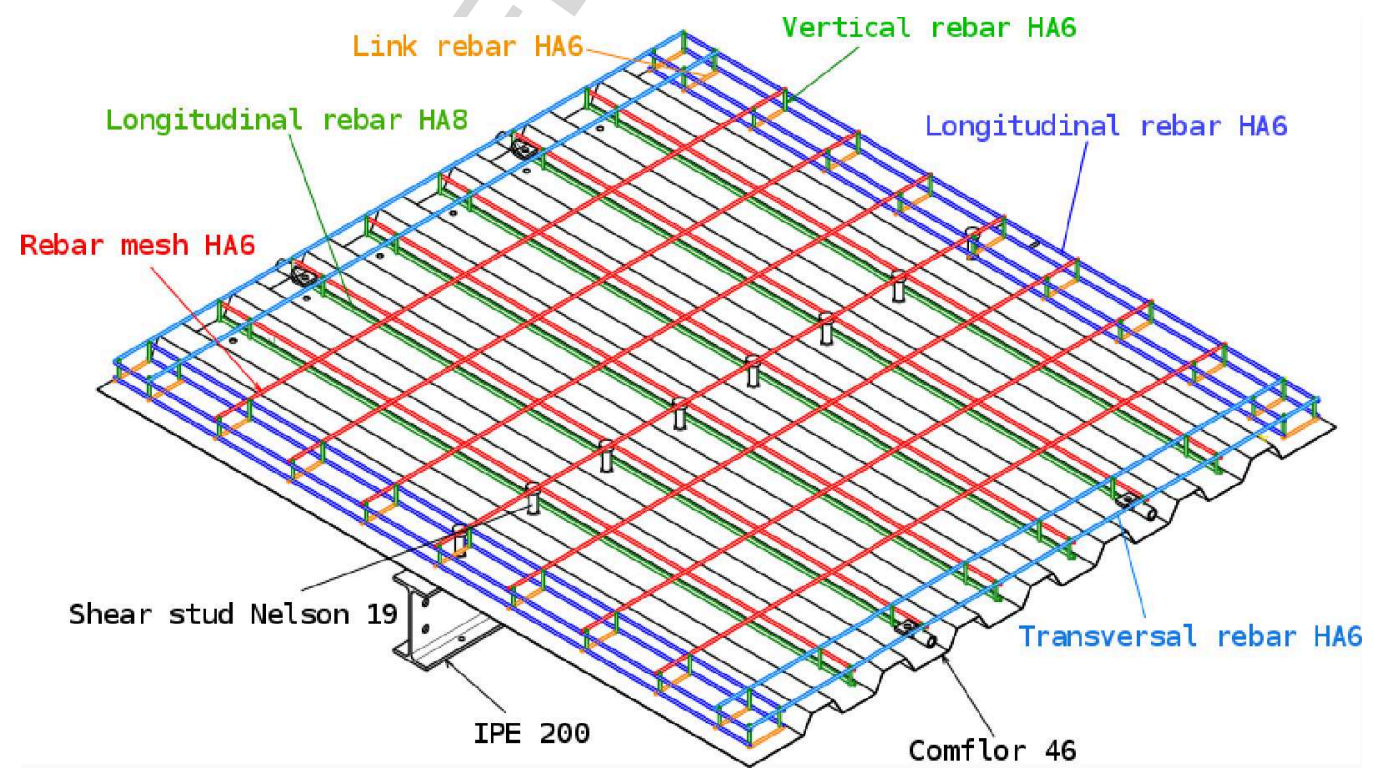

Figure 5: Composite beam specimen

is of a strength class C25/30 formulated according to the norm BPS EN 206-1, with an environment class of XF1, a 0.4 chloride and the maximum dimension of the gravel at $16 \mathrm{~mm}$. All the three specimens were concreted on 30/07/2014. A series of compressive cylinder tests 
Table 1: Results of tensile coupon tests.

\begin{tabular}{|c|c|c|c|c|c|}
\hline Material & Coupon & $f_{y}[\mathrm{MPa}]$ & $f_{y m}[\mathrm{MPa}]$ & $f_{u}[\mathrm{MPa}]$ & $f_{u m}[\mathrm{MPa}]$ \\
\hline \multirow{6}{*}{ Comfor 46} & 1 & 314.85 & & 379.75 & \multirow{6}{*}{382.03} \\
\hline & 2 & 307.93 & & 380.84 & \\
\hline & 3 & 309.73 & & 383.76 & \\
\hline & 4 & 315.02 & & 383.33 & \\
\hline & 5 & 315.67 & & 382.60 & \\
\hline & 6 & 313.45 & 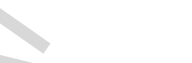 & 381.89 & \\
\hline \multirow{6}{*}{ HA-8mm rebar } & 1 & 494.71 & \multirow{6}{*}{500.66} & 630.45 & \multirow{6}{*}{629.68} \\
\hline & 2 & 492.06 & & 629.69 & \\
\hline & 3 & & & 621.11 & \\
\hline & 4 & 501.19 & & 627.47 & \\
\hline & & 489.74 & & 624.81 & \\
\hline & 6 & 528.85 & & 641.53 & \\
\hline \multirow{6}{*}{ HA-6mm rebar } & 1 & 507.54 & \multirow{6}{*}{511.04} & 634.07 & \multirow{6}{*}{631.54} \\
\hline & 2 & 513.23 & & 631.00 & \\
\hline & 3 & 508.52 & & 629.50 & \\
\hline & 4 & 507.57 & & 616.14 & \\
\hline & 5 & 515.25 & & 639.93 & \\
\hline & 6 & 514.12 & & 638.63 & \\
\hline \multirow{6}{*}{ Shear stud } & 1 & 406.98 & \multirow{6}{*}{432.57} & 496.71 & \multirow{6}{*}{520.04} \\
\hline & 2 & 442.20 & & 539.69 & \\
\hline & 3 & 473.64 & & 545.53 & \\
\hline & 4 & 417.30 & & 507.82 & \\
\hline & 5 & 405.22 & & 499.03 & \\
\hline & 6 & 450.09 & & 531.48 & \\
\hline
\end{tabular}


Table 2: Results of cylinder compressive tests

\begin{tabular}{|c|c|c|c|}
\hline Test date & Age [days $]$ & $f_{c}[\mathrm{MPa}]$ & $f_{c m}[\mathrm{MPa}]$ \\
\hline \multirow{2}{*}{$01 / 09 / 2014$} & & 37.23 & \\
& 33 & 36.26 & 37.15 \\
& & 37.96 & \\
\hline \multirow{2}{*}{$06 / 11 / 2014$} & 99 & 42.98 & \\
& & 13.47 & 43.40 \\
& & 43.82 & \\
& & 41.87 & \\
$28 / 11 / 2014$ & 121 & 42.63 & 42.25 \\
& & 16.24 & \\
\hline
\end{tabular}

of concrete specimens were carried out at the age of 33 days, 99 days and 121 days. The tests at the age of 33 days were to determine the nominal strength of the concrete while the tests at 99 days and 121 days were made before and after the initial stiffness tests respectively in order to know the concrete strength at the approximated time of testing. The results of the cylinder compressive tests are summarized in Table 2 where the concrete strength, the mean value of concrete strengths are denoted by $f_{c}$ and $f_{c m}$, respectively. Among the cylinder tests, two tests were not taken into consideration due to erroneous results. The concrete class specified in the design of reference building was C30/37; the mean value of the concrete strength from the tests was obtained at $f_{c m}=37.15 \mathrm{MPa}$, which is quite comparable to the mean value theoretically assumed for the concrete C30/37 $\left(f_{c m}=38 \mathrm{MPa}\right)$.

\section{Push-out Test: Experimental Setup and Loading Procedure}

The experimental setup of the horizontal push-out test of the composite floor was positioned on a rigid frame system (meshed floor and reacting frame), as shown in Fig. 6. The rigid frame system was designed to have large rigidity so that its displacements in all directions are not allowed to occur. Local buckling of the elements in the rigid system is also avoided by stiffeners. Having one end fixed to the reacting frame by bolts, a hydraulic 
servo controlled actuator applied a horizontal load on one of the IPE 200 beam's end crosssections. This force jack has a load capacity of $500 \mathrm{kN}$ for the initial and residual stiffness test and $1500 \mathrm{kN}$ for the residual ultimate resistance test. At the other end of the specimen, the composite floor was placed in contact with a rigid steel beam all along its edge's width (See detail A and C in Fig. 6). The uplift displacement of the floor at this edge was prevented by an L-shape steel profile (See detail A). The composite beam specimen was placed horizontally on two vertical supporting steel columns called potelet. Each interface between the IPE-200 steel beam and the potelet was equipped with double greased PTFE plates to reduce friction between the surfaces. The poletets are fixed to the rigid meshed floor by bolts. The uplift displacement of the steel beam was also avoided by bolts in slotted holes (only horizontal movement is allowed) as shown in Fig. 7. According to the formula

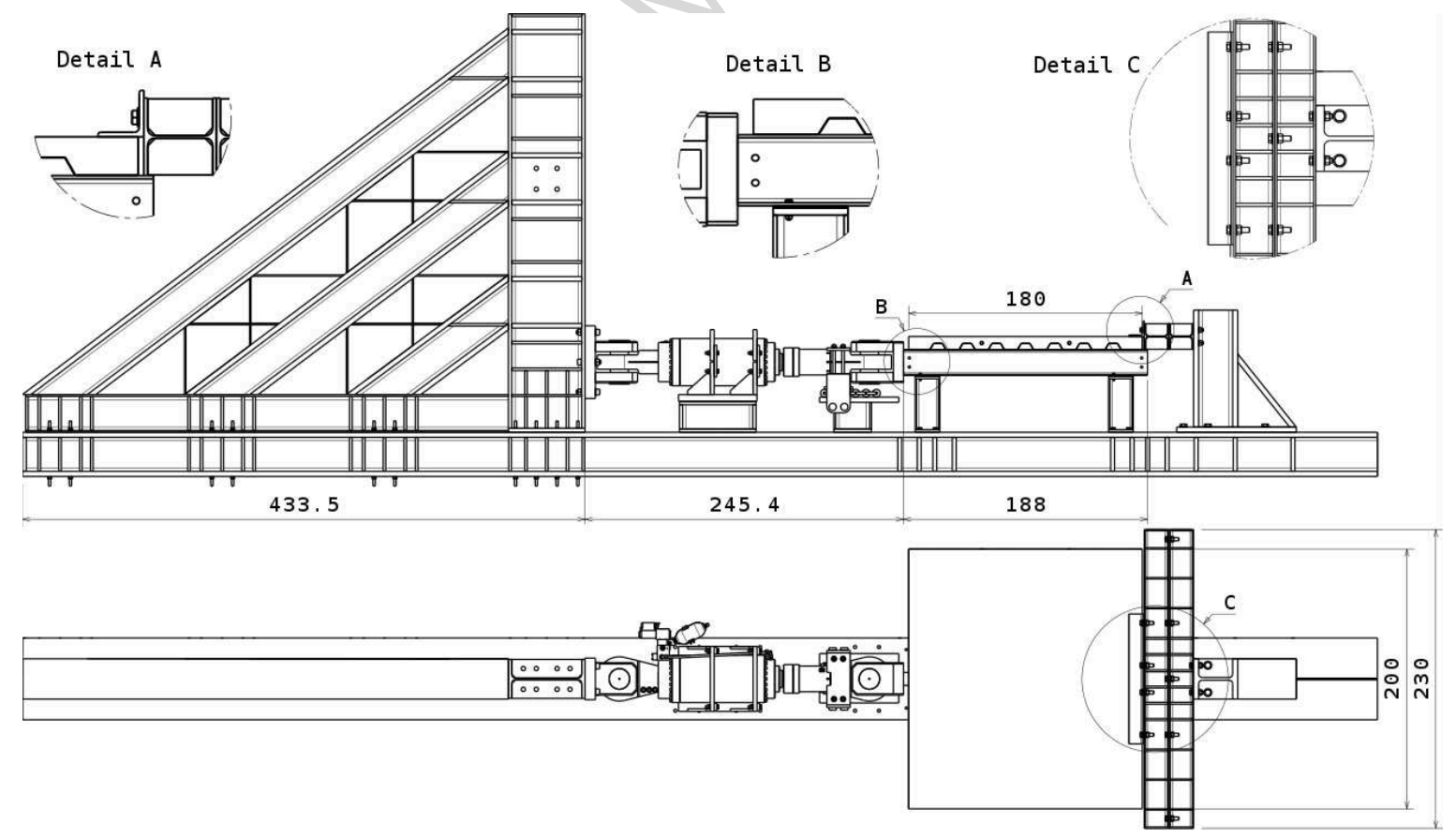

Figure 6: Push-out test setup

provided in EN 1994.1.1/6.6.3.1, the shear resistance of the 19-mm shear stud with nominal yield strength of $450 \mathrm{MPa}$ in solid concrete panel is provided by

$$
P_{R d, c}=\min \left(P_{R d, 1}, P_{R d, 2}\right)=81.7 \mathrm{kN}
$$




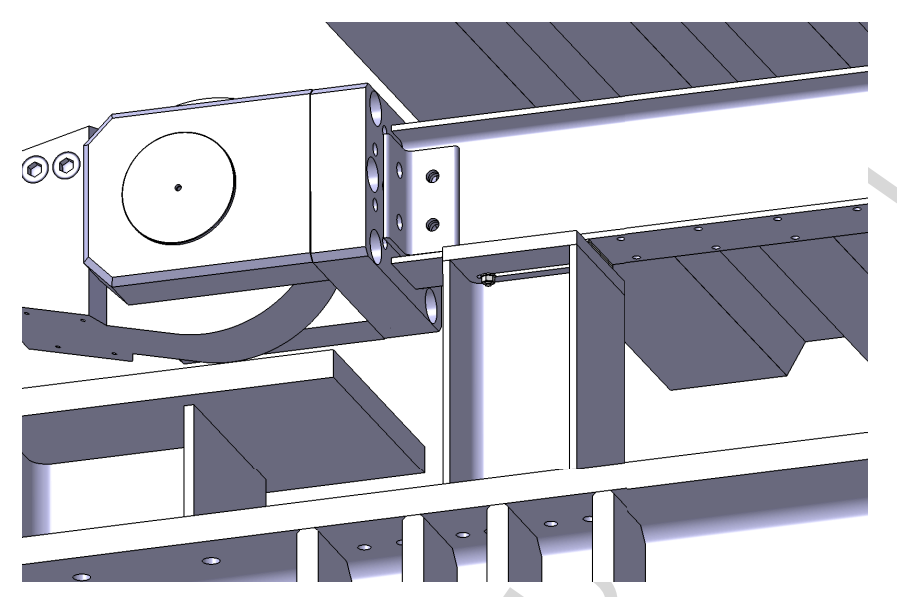

Figure 7: Interface between the potelet and the IPE 200

in which

$$
\begin{gathered}
P_{R d, 1}=\frac{0.8 \times f_{u} \times \frac{\pi d^{2}}{4}}{\gamma_{v}}=\frac{0.8 \times 450 \times \frac{\pi 19^{2}}{4}}{\gamma_{v}}=81.7 \mathrm{kN} \\
P_{R d, 2}=\frac{0.29 \times a \times d^{2} \times \sqrt{f_{c k} \times E_{c}}}{\gamma_{v} \times 1000}=\frac{0.29 \times 1 \times 19^{2} \times \sqrt{35 \times 30 \times 10^{3}}}{1.25 \times 1000}=85.8 \mathrm{kN}
\end{gathered}
$$

where $f_{u}$ is nominal yield strength of the stud; $\gamma_{v}$, safety factor; $d$, diameter of the stud; $f_{c k}$, nominal strength of concrete; $E_{c}$, Young modulus of concrete; $a=1$.

However, the shear resistance of the stud in the sheeting profile, which is the design shear resistance per stud, is determined by multiplying the shear resistance per stud in solid concrete panel $P_{R d, c}$ with a reduction factor $k_{t}$ as

$$
P_{R d, s}=k_{t} \times P_{R d, c}=81.7 \times 1.04=85 \mathrm{kN}
$$

in which

$$
k_{t}=\frac{0.7 b_{0}}{n_{r} h_{s}}\left(\frac{h_{\text {stud }}}{h_{s}}-1\right)=\frac{0.7 \times 105}{\sqrt{1} \times 46}\left(\frac{76}{46}-1\right)=1.04
$$

with $n_{r}$, number of stud per trough; $b_{0}$, average width of trough; $h_{s}$, height of the sheeting profile.

The estimated shear resistance per stud is then calculated by multiplying the safety 
factor with the design shear resistance as following

$$
P_{R d}=\gamma_{v} \times P_{R d, s}=1.25 \times 85=106.2 \mathrm{kN}
$$

For 8 studs, the ultimate shear resistance was approximately at $850 \mathrm{kN}$. The capacity of the force jack of $1500 \mathrm{kN}$ and the design of the bracing system and test setup for the load of $1500 \mathrm{kN}$ were sufficiently strong to ensure proper test conditions.

In the push-out test for initial and residual stiffness, the maximum load was limited at $100 \mathrm{kN}$ to avoid possible cracking in concrete material. Three phases of the servo-controlled loading procedure were exerted:

- The load was increased until $10 \mathrm{kN}$;

- 10 cycles of loading and unloading procedure between 10 and $20 \mathrm{kN}$ were applied;

- 5 cycles of loading and unloading procedure between 10 and $100 \mathrm{kN}$ were applied.

In push-out test for residual ultimate resistance, the load was increasingly applied until the collapse of the specimen.

The longitudinal slip was measured by LVDT sensors with a maximum displacement capacity of $+/-2.5 \mathrm{~mm}$, placed at ten locations as indicated in Fig. 8, for the initial and residual stiffness push-out test. On the other hand, for residual ultimate resistance push-out test, the longitudinal slip was recorded only at four locations where LVDT sensors with a maximum displacement capacity of $+/-25 \mathrm{~mm}$ were located (see Fig. 9). Fig. 10 gives a general view of specimen and test setup. 


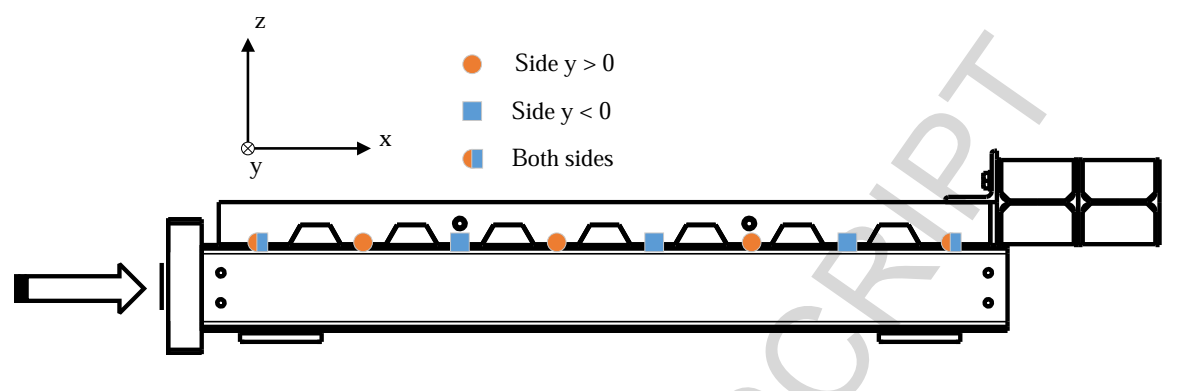

Figure 8: LVDT sensors: initial and residual stiffness test

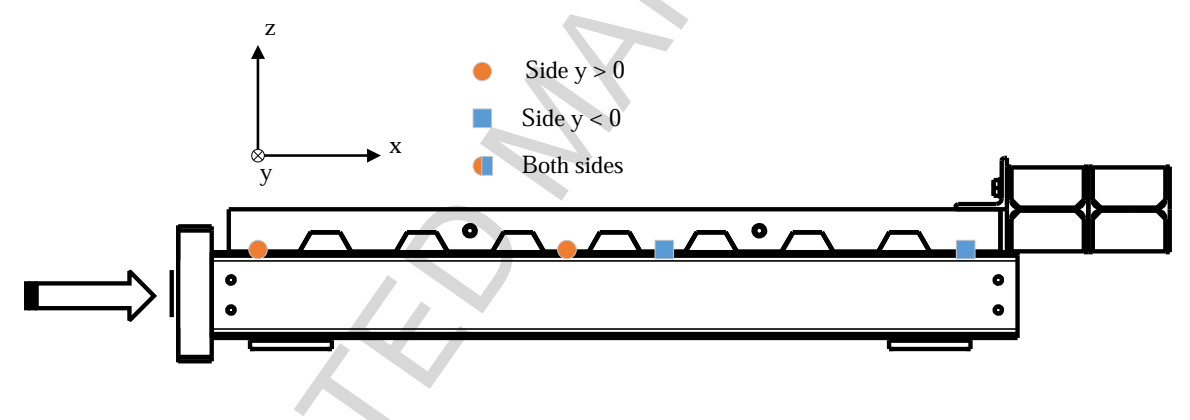

Figure 9: LVDT sensors: residual ultimate resistance test

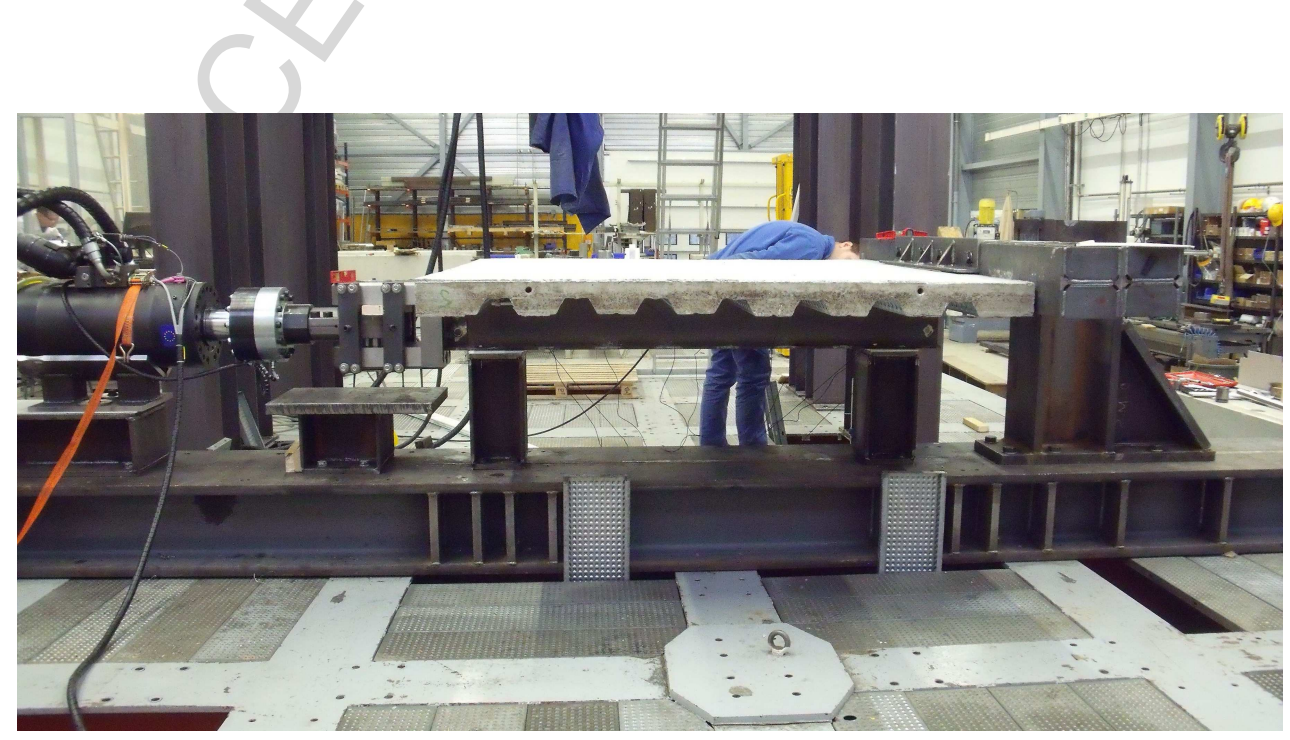

Figure 10: Push out test: side view of experimental setup 


\section{Pull-out Test: Experimental Setup and Loading Procedure}

It can be inferred from the results of the numerical simulations of blast tests on the specimen, which were done by Tecnalia within the BASIS project [23], that the inertia effect is negligible. Hence, to reproduce the pre-damage of the explosion, a supplementary pull-out test that applies a quasi-static load was suggested. The experimental set-up of the pull-out test is illustrated in Fig. 11. In this setup, the IPE-200 steel beam of the composite beam specimen was connected to a steel frame by 32 HM-10 bolts arranged into two lines. The frame consisted of an HEB-300 profile at top, an HEB-400 profile at bottom and two HEA-200 profiles. Two hydraulic servo controlled actuators with a capacity of $500 \mathrm{kN}$ applied vertical loads on the HEB-300 profile of the frame symmetrically so that a uniform distribution of tension forces and damaging in every stud can be achieved. The composite beam specimen was placed at the Comflor side on two HEB-300 stringers parallel to the IPE-200 steel beam. The interface between the Comfor steel sheeting and the stringers was made by two greased PTFE plates to reduce friction between the surfaces. The stringers were hinged to UPN-220 supporting columns with free rotation. Potentiometer sensors were placed at three locations (See Fig. 12(a)) at mid-span to measure the global displacements of the specimen. A sensor with a maximum displacement capacity of $+/-100 \mathrm{~mm}$ was used at the locations below the bottom surface of the HEB-400 profile whereas sensors with a maximum displacement capacity of $+/-25 \mathrm{~mm}$ were used at the locations below the bottom surface of the stringers. The vertical uplift of the stud connectors were recorded by 8 LVDT sensors, with a maximum displacement capacity of $+/-2.5 \mathrm{~mm}$. These sensors were located along the IPE-200 steel beam, see Fig. 12(b). From the measurements made during the blast test at INERIS, the load applied on the steel beam was $280 \mathrm{kN}$. However, the test set-up was designed for an applied load up to $800 \mathrm{kN}$. Due to the uncertainty on the maximum applied load that would not completely damage the specimen, the loading procedure follows two phases:

- First, the specimen was loaded up to $70 \mathrm{kN}$, and the initial stiffness is determined based on force-mean displacement curve. 

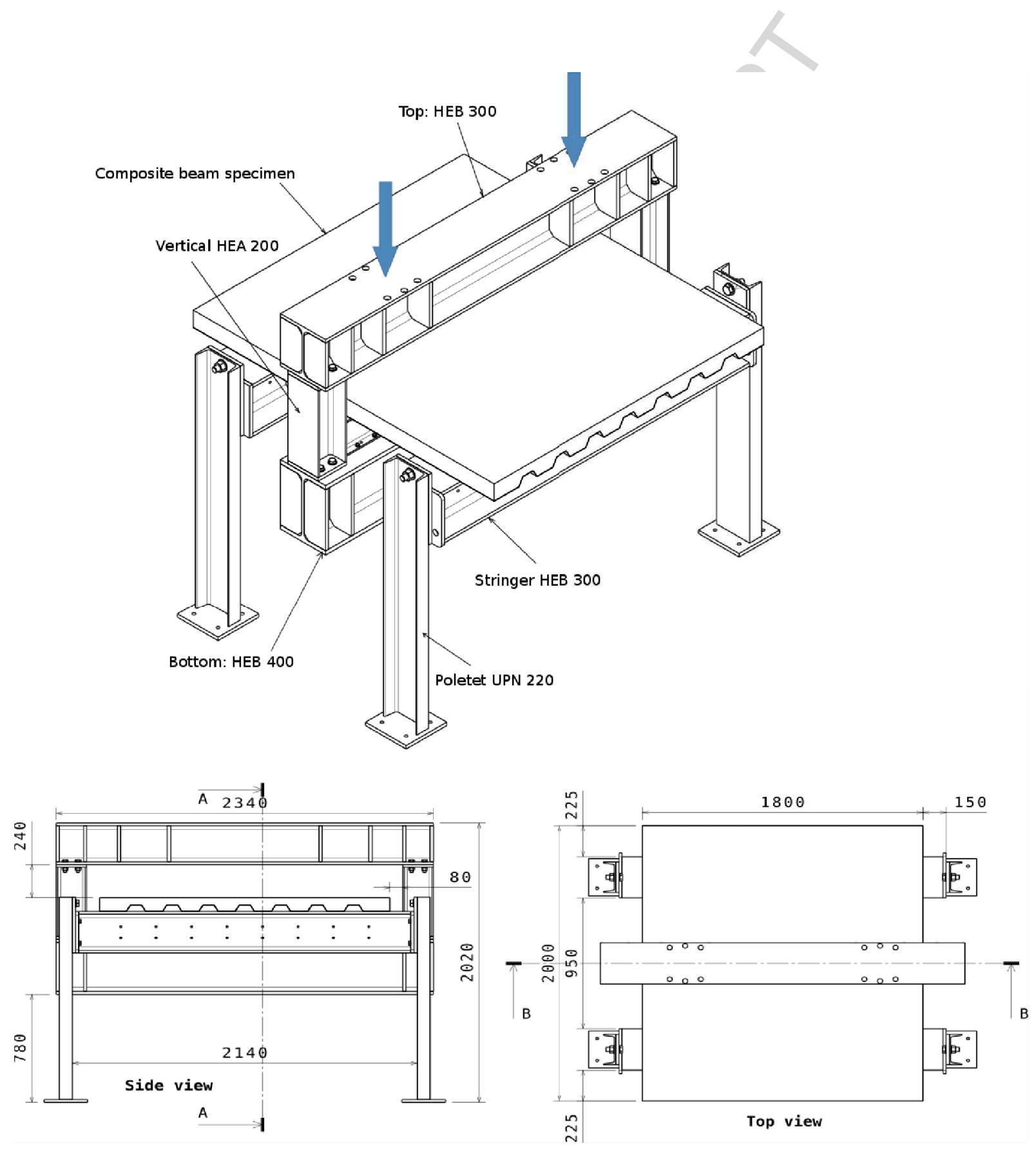

Figure 11: Pull-out test set-up 
- Then, the loading was resumed with low rate so that it could be stopped if the displacement lead to a secant stiffness that was ten time smaller than the computed initial stiffness or if a significant change of the evolution of the specimen could be visually observed.

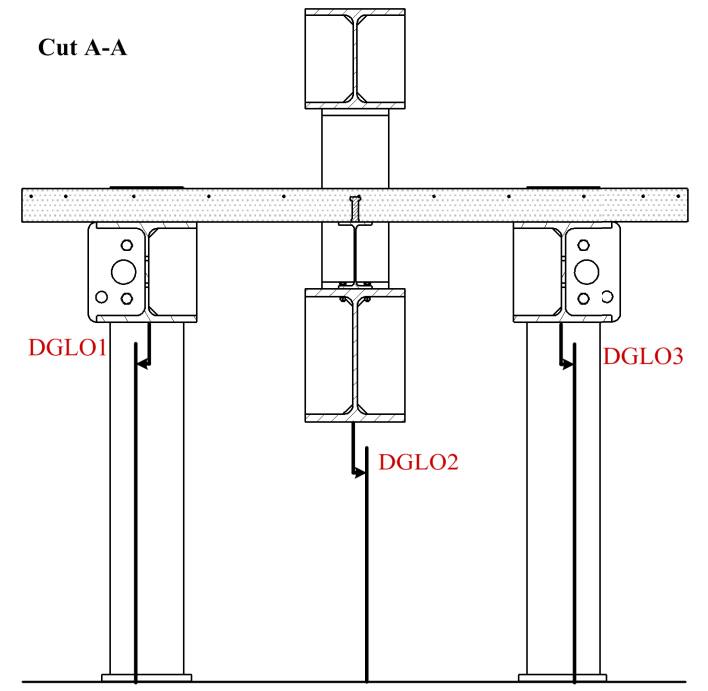

(a)

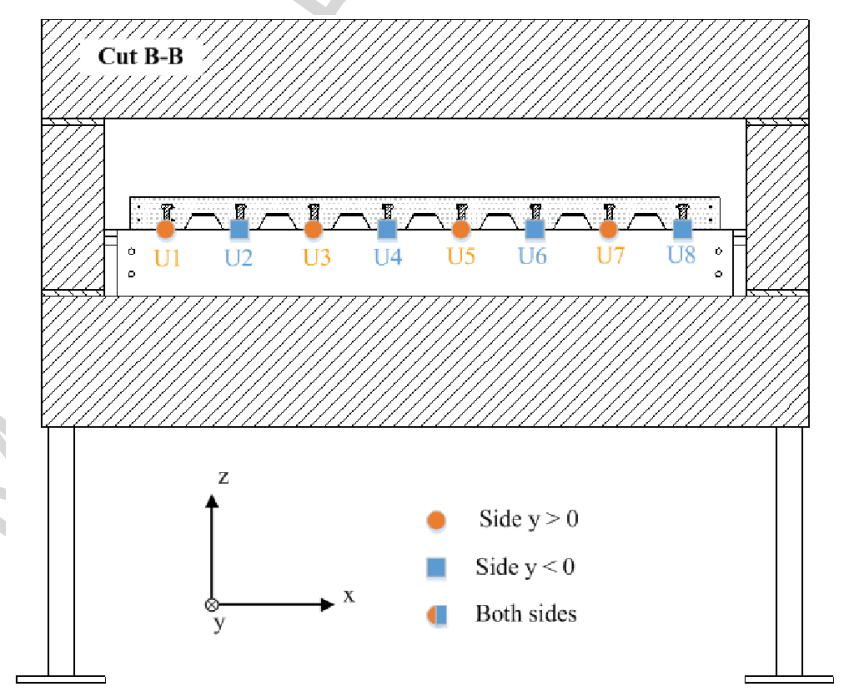

(b)

Figure 12: (a). Potentiometer sensors (b). LVDT sensors.

\section{Pull-out Test: Experimental Results}

The pull-out test of the third specimen was carried out on 28/04/2015. Two force actuators applied downward forces on the specimen by imposing displacements, and the force history was recorded by the Deltec force sensors. The relative displacement between the two force jacks was adjusted along the test in order to maintain similar forces in each jack. Two cycles of loading and unloading between a total force of 30 and $70 \mathrm{kN}$ were made to acquire information about the initial stiffness. The force- displacement curve using global displacement is plotted in Fig. 13. The loading was stopped as soon as the force was seen decreased with increasing displacement. The maximum force attained was measured to 162.6 $\mathrm{kN}$, which gives approximately $20 \mathrm{kN}$ per stud. The evolution of the uplift displacements measured by the LVDT sensors is presented in Fig. 15. The uplift displacement grew larger 
at the extremities. It was considered that the studs had reached their maximum limit load with the evidence of the uplift displacement ranging between $0.6 \mathrm{~mm}$ to $2.3 \mathrm{~mm}$. It was concluded that the yielding of rebars happened as a plateau was observed in the forcedisplacement curve. The cracking of concrete after pull-out test is shown in Fig. 14. The concrete zones around the shear connectors were surely damaged because large values of beam-concrete uplifts were measured. Yielding of steel sheet was also noticed.

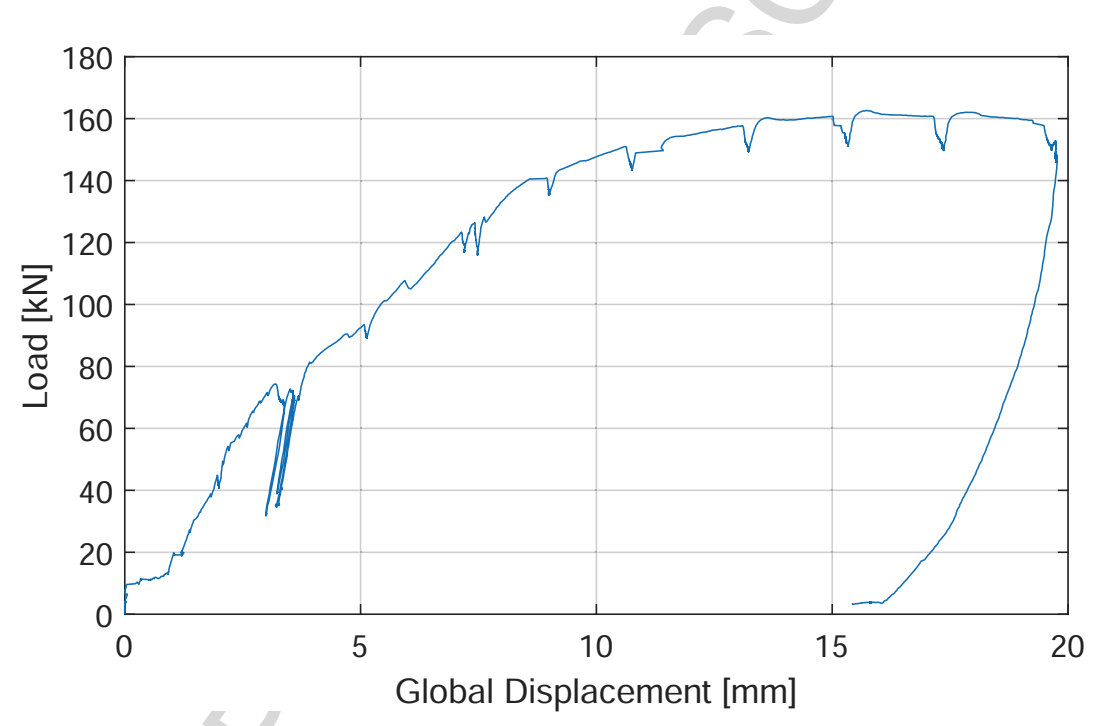

Figure 13: Pull-out test: force-displacement curve using global displacement

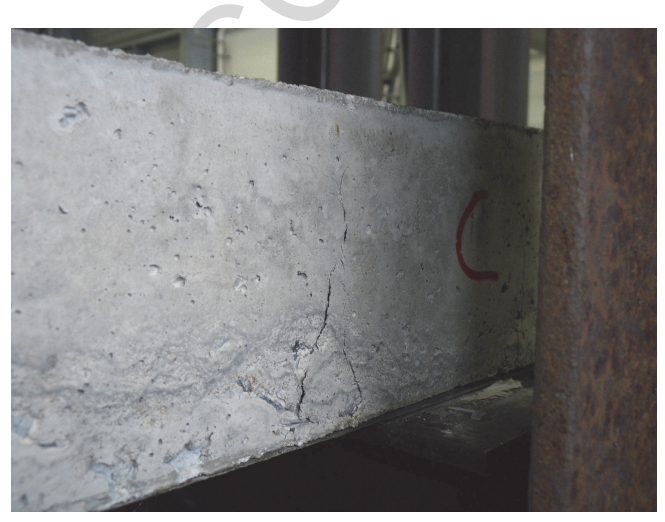

(a)

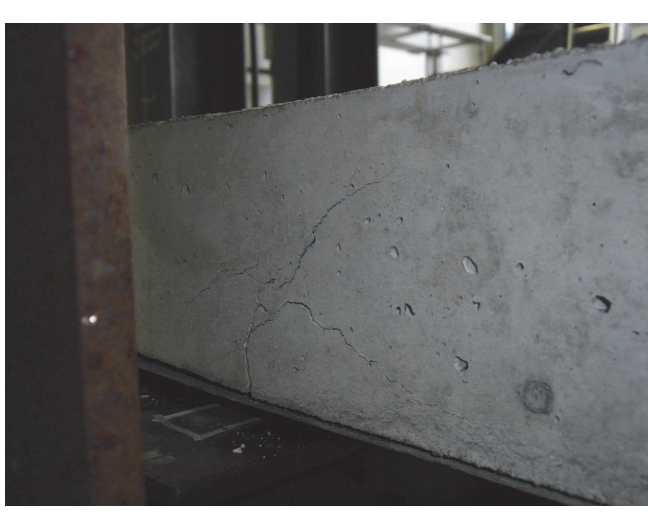

(b)

Figure 14: Cracking of concrete at both sides of the composite beam specimen 


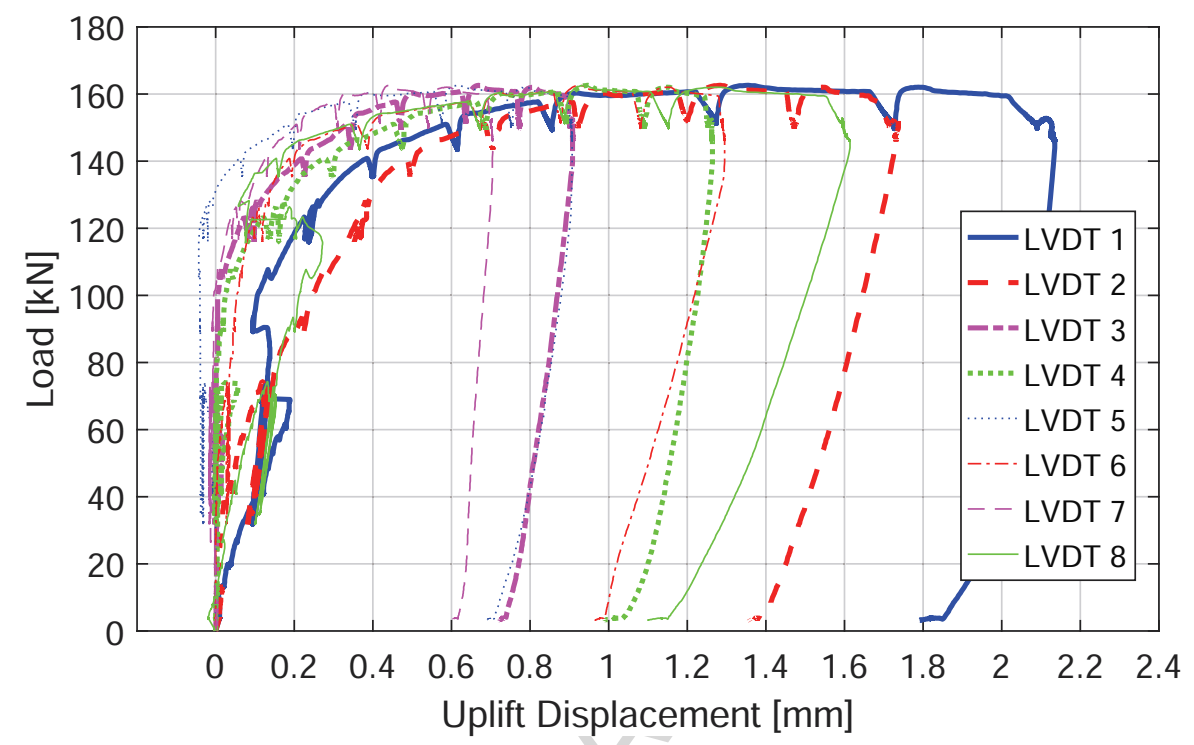

Figure 15: Pull-out test: force-slip curve

\section{Push-out Test: Experimental Results}

\subsection{Initial stiffness test}

Three push-out tests for initial stiffness of the composite beam specimens were carried out on $03 / 11 / 2014,05 / 11 / 2014$ and 06/11/2014 respectively. For these tests, the contact between the concrete and the support was limited to a width of $60 \mathrm{~cm}$ only. The slip recorded by the LVDT sensors at the applied load of $100 \mathrm{kN}$ are reported in Fig. 16. It appears that the slips are larger at the extremities than in the middle, making uneven distribution of the slips. Similar results were obtained in specimen 1 and 3 while the stud near the support seem to have been excessively load-concentrated in specimen 2, leading to decrease in forces at the other studs. Such local effects can be expected at very low level of applied shear load due to possible parasitic phenomena. The force-slip curves for all the three specimens are plotted in Fig. 17.

To make a verification of the result with the analytical expression [24], the force at each stud is calculated using the expression in Eq. (7). The force summed for all the studs are presented in Table 3, and the level of magnitude of the force agrees well with the actual 
Table 3: Initial stiffness push-out test: total force of all the studs from slip measurement

\begin{tabular}{|c|c|c|c|}
\hline Specimen & 1 & 2 & 3 \\
\hline Total force $[\mathrm{kN}]$ & 106.5 & 73.5 & 90 \\
\hline
\end{tabular}

applied load of $100 \mathrm{kN}$.

$$
P=P_{u}\left(1-e^{-1.22 S^{0.59}}\right)
$$

where $P_{u}=106.2 \mathrm{kN}$ is the ultimate resistance of the stud (see Eq. (6)) and $S$ is the slip of the stud.

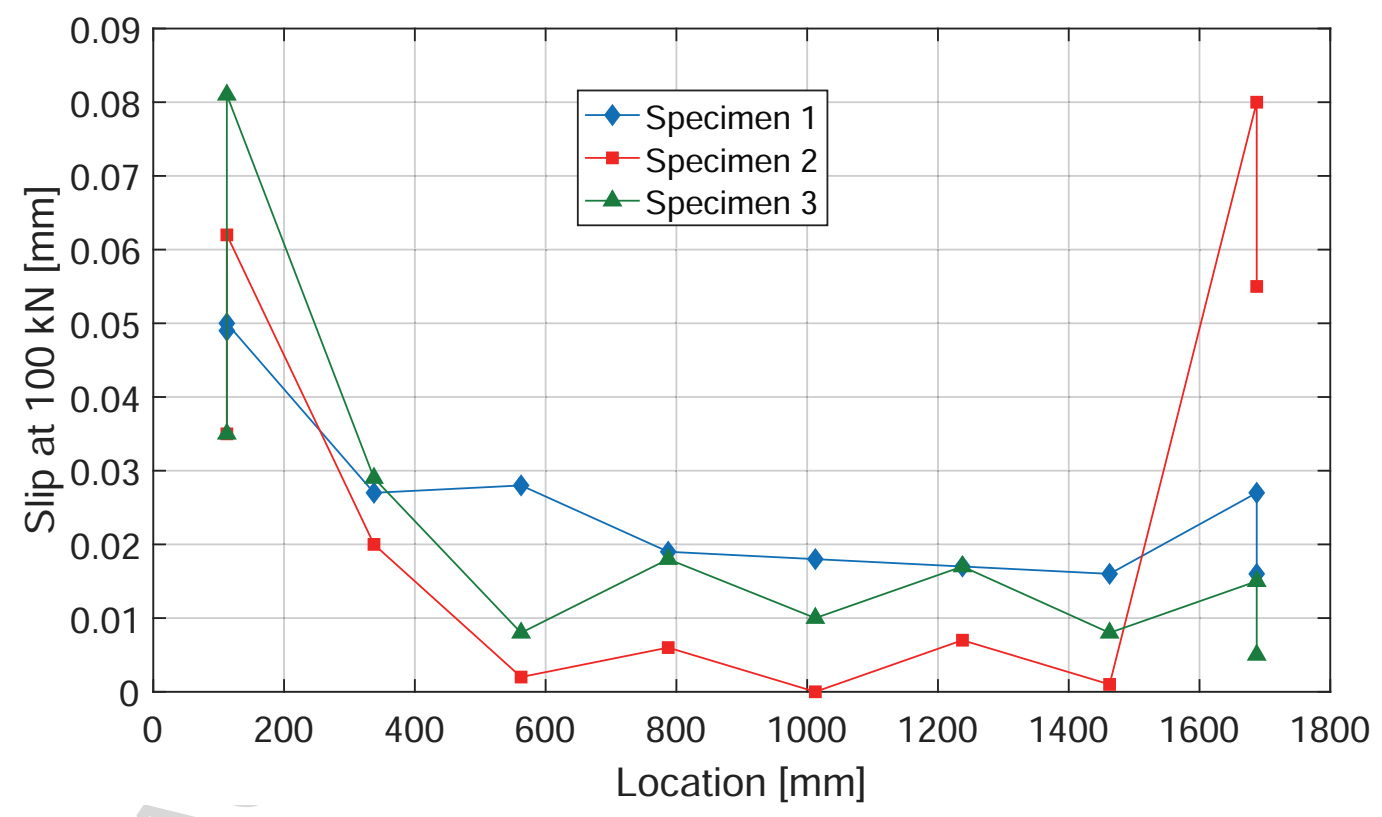

Figure 16: Initial stiffness push-oute test: Slips at the applied load of $100 \mathrm{kN}$ 


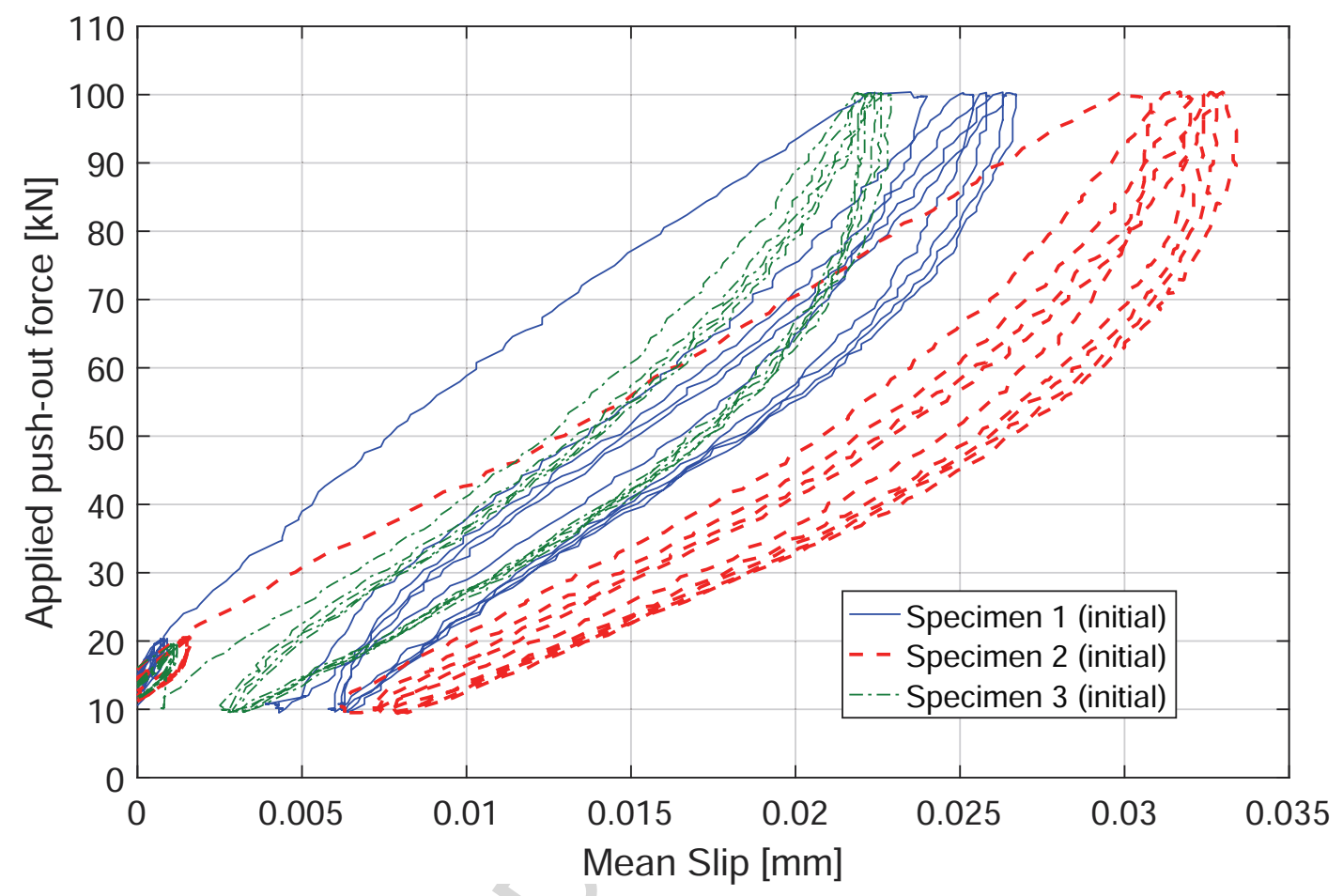

Figure 17: Initial stiffness push-out test: force-slip curves

\subsection{Residual stiffness test}

After pull-out test, the third specimen was submitted to push-out test for residual stiffness on $07 / 05 / 2015$. For this test, the contact between the concrete and the support was limited to a width of $60 \mathrm{~cm}$ only. The evolution of slips with the force is shown in Fig. 18. The response behavior in the first cycle of the loading and unloading between 10 and 100 $\mathrm{kN}$ differed from the other four cycles. This can be explained by the fact that the concrete zone around the stud must have been damaged by the pull-out test, which required some movement in the first cycle to obtain good contact again. The comparison is also made in Fig. 19 between the mean slips obtained in the initial stiffness push-out test and the slip observed in the residual stiffness test for the first and the last loading/unloading cycle. The mean value among the slips are summarized in Table 4. It can be approximately deduced from the results given in Table 4 that the residual stiffness of the composite beam equals to the initial stiffness divided by a factor in a range between 10 and 20. The force-mean slip 
curves of all the three specimens in the initial stiffness test and the residual stiffness test for the last cycle of loading are presented in Fig. 20.

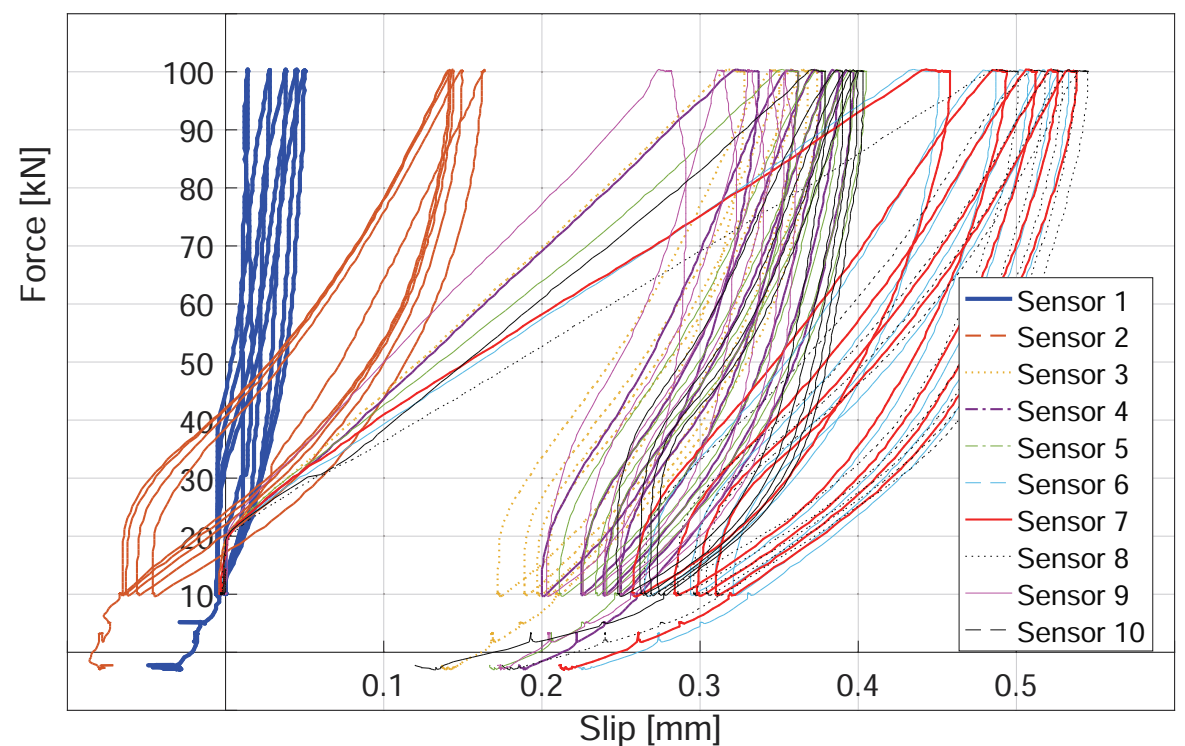

Figure 18: Residual stiffness push-out test: force-slip curves

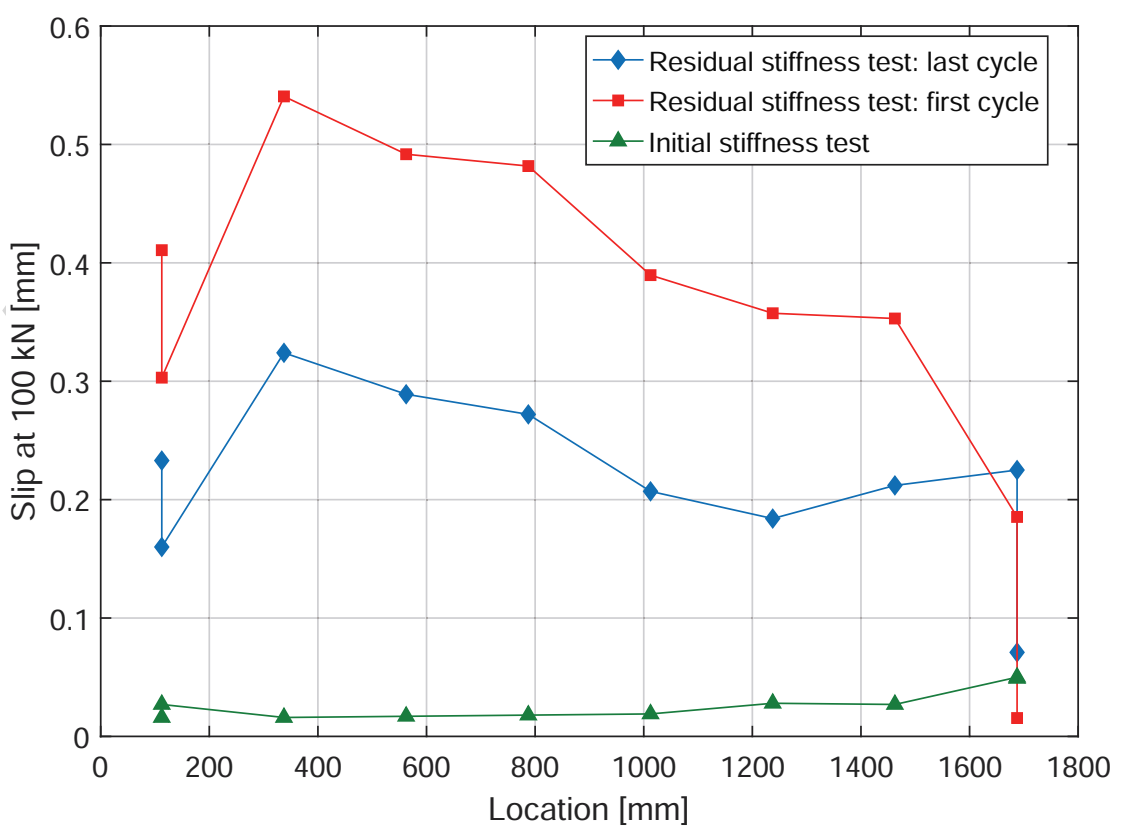

Figure 19: Push-out test: comparison of slips at $100 \mathrm{kN}$ 


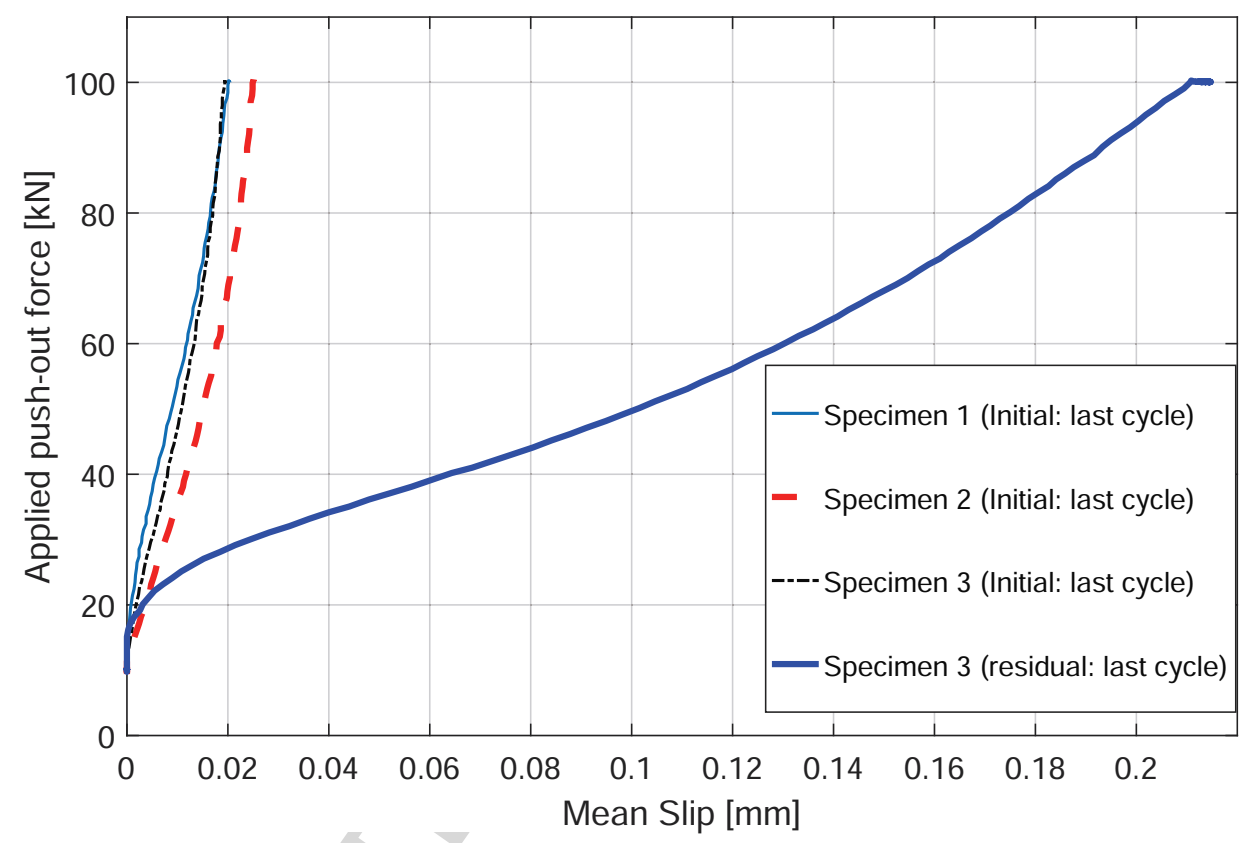

Figure 20: Push-out test: comparison of force-slip curves for the last cycle

Table 4: Residual stiffness push-out test: mean slip of the studs at $100 \mathrm{kN}$

\begin{tabular}{|c|c|c|}
\hline Test & Mean slip $[\mathrm{mm}]$ & Ratio Residual/Initial stiffness \\
\hline Initial stiffness test & 0.022 & 1 \\
\hline Residual stiffness test - last cycle & 0.23 & 10.4 \\
\hline Residual stiffness test - first cycle & 0.38 & 17.4 \\
\hline
\end{tabular}




\subsection{Residual ultimate resistance test}

To acquire the residual resistance of the composite beam specimen after pre-damaging by pull-out force, the push-out test of the specimen up to the ruin of the specimen was performed on 13/05/2015. The evolution of the mean slip against the force is presented in Fig. 21. There was an accidental move of the test setup, which made an unloading at around $400 \mathrm{kN}$. However, the reloading reached the same envelop curve. The maximum load corresponding to the residual resistance of the specimen was attained at $530 \mathrm{kN}$. Although the initial resistance was not determined from experimental test, the formula provided in EN 1994.1.1/6.6.3.1 gives an initial resistance of $850 \mathrm{kN}$. From that, it can be deduced that the resistance of the composite beam is reduced by around 40 percent for a pre-damaging that has led to the yielding of the rebars under pull-out action with a mean uplift of 1.3 $\mathrm{mm}$.

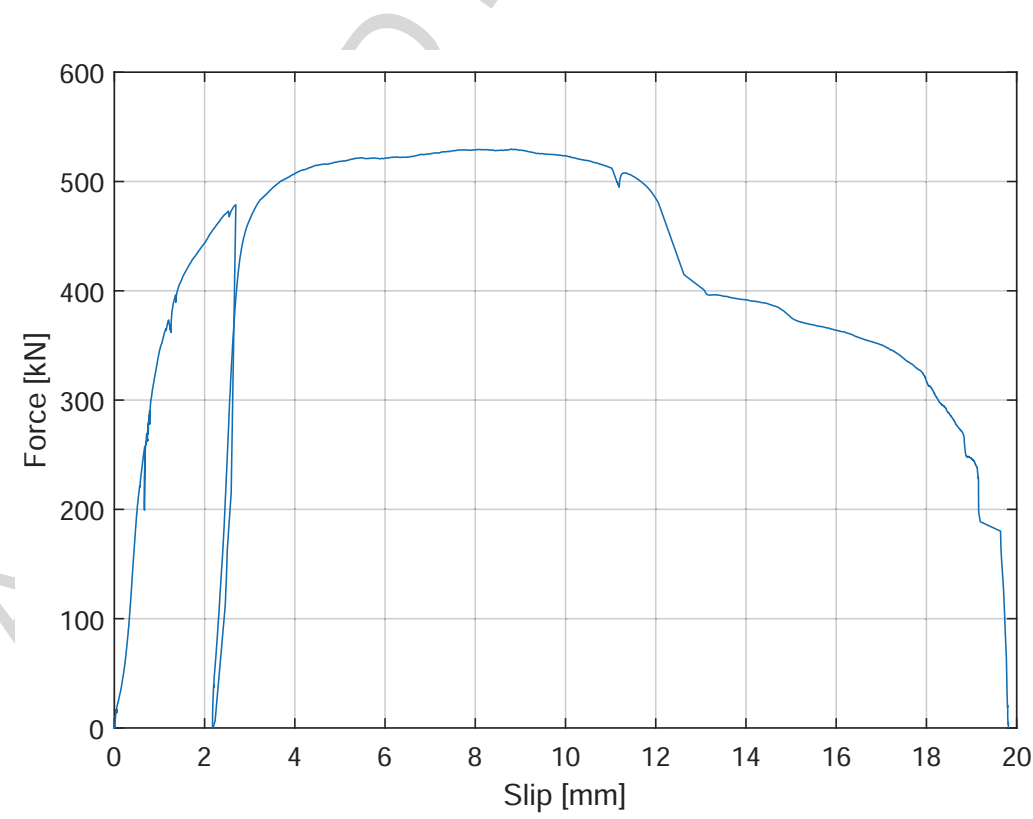

Figure 21: Residual resistance push-out test: force-slip curve 


\section{Numerical modelling}

\subsection{Initial stiffness test - Simplified model}

This section presents a simplified model of the composite beam specimen with a purpose to verify the accuracy of the initial stiffness test with respect to the analytical formula in Eq. (7) and vice versa. This simplified model was created in ABAQUS/CAE using beam elements for the composite floor and the IPE-200 steel beam. Elastic model was used for material behavior of the composite floor and the IPE-200 beam. The shear connectors are modelled by two rigid elements that are linked by CARTESIAN-type connector (See Fig. 22). CARTESIAN-type connector is an option available in ABAQUS, which provides a connection between two nodes at which the change of the position is measured at the three local directions by defining a local origin at one node, and the change is measured at the other node in reference to the first one. Not imposing any kinematic constraints, such connector's behavior can be assigned separately with respect to different directions. Hence, the behavior property of the CARTESIAN-type connector is defined by a large stiffness whereas, in horizontal direction, the force-displacement relation is defined following Eq. (7).

MPC TIE (Multi Point Constraint), an option available in ABAQUS, is used to tie the concrete floor and the IPE-200 steel beam to the Cartesian connector, which has been put at the level of steel-concrete interface, see Fig. 22.

\subsection{All test - Full solid model}

\subsubsection{Geometry, constraint and contact interaction}

In this section, a full model of the composite beam specimen is presented. Created in ABAQUS/Explicit, the concrete, shear stud and IPE-200 steel beam were modelled using a linear 8-node reduced integration hexahedral continuum element (C3D8R) whereas the profiled steel sheet was modelled by a linear 4-node reduced integration quadrilateral shell element (S4R). The meshed rebars were, on the other hand, modelled by a linear 2-node 3D truss element (T3D2). Each of the material parts was partitioned in a way that structured meshing technique could be applied. The concrete floor part was cut out at the zone where the studs were located. The contact interaction with general contact was used to model the 


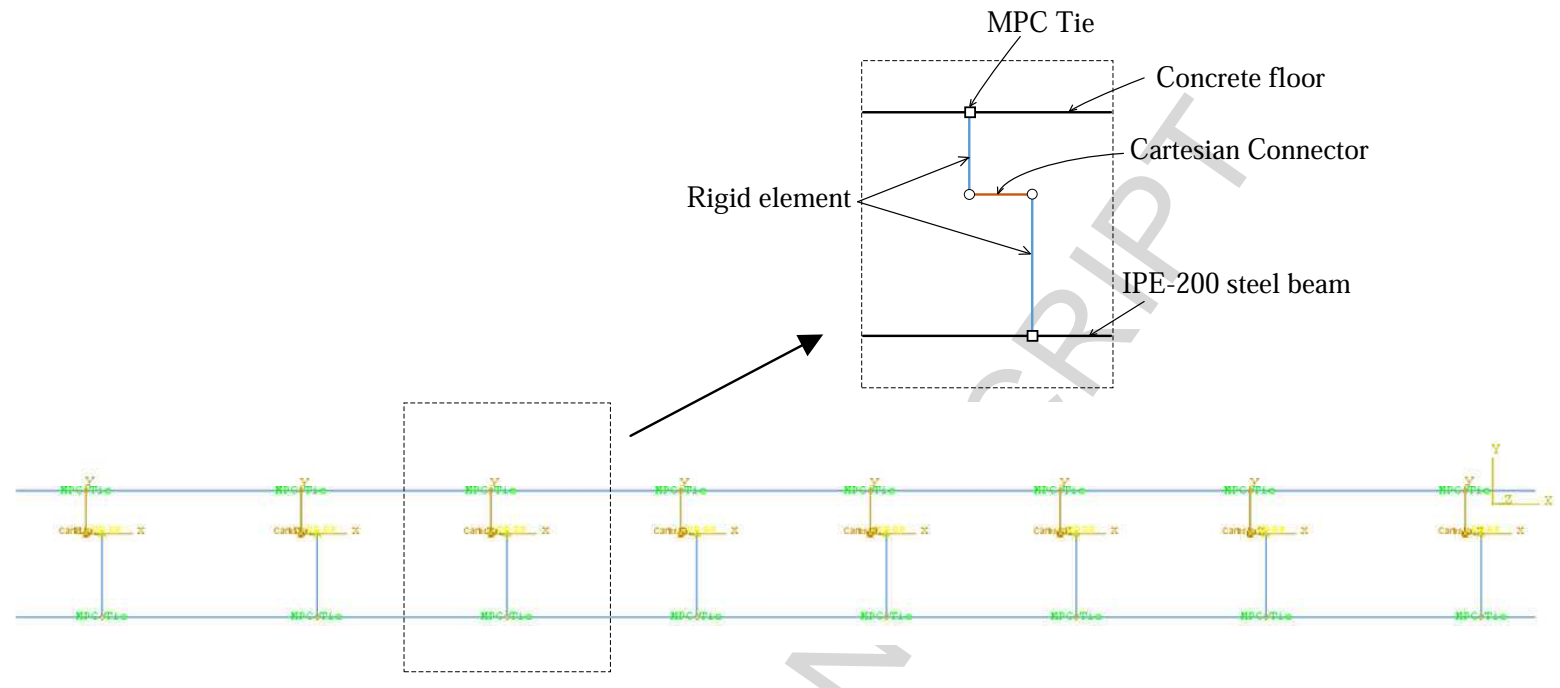

Figure 22: FE simulation: simplified model

contact behavior between the concrete panel and shear studs, concrete panel and profiled steel sheeting, and profiled steel sheet and HEB-300/IPE-200 steel beams. Hard contact and friction penalty were employed for the normal and tangential behavior respectively. A friction coefficient of 0.5 was used for the contacts between the profiled steel sheet and the concrete panel and between the shear studs and the concrete panel, and 0.1 for the other contacts. Tie constraints were used to tie shear studs to the IPE-200 steel beam. The rebar mesh was embedded in the concrete panel. The HEB-300 steel beams that support the specimen are constrained to a reference point using Rigid-Body Constraint. The configuration of the modelling used to simulate the pull-out test is shown in Fig. 23. The boundary conditions for the pull-out test and the push-out test are illustrated in Fig. 24(a) and 24(b), respectively. In the pull-out test, the reference points that constrain the HEB-300 steel beams are fixed in all directions except the rotation around x-axis. In the push-out test, the picked bottom surfaces of the IPE-200 steel beam are fixed in vertical direction (y-axis), the picked edge surface of the concrete panel is fixed in horizontal direction (x-axis), the picked top surface of the concrete panel is fixed in vertical direction (y-axis), and the reference points that constrain the HEB-300 steel beams are fixed in all directions except the rotation around $\mathrm{x}$-axis. 


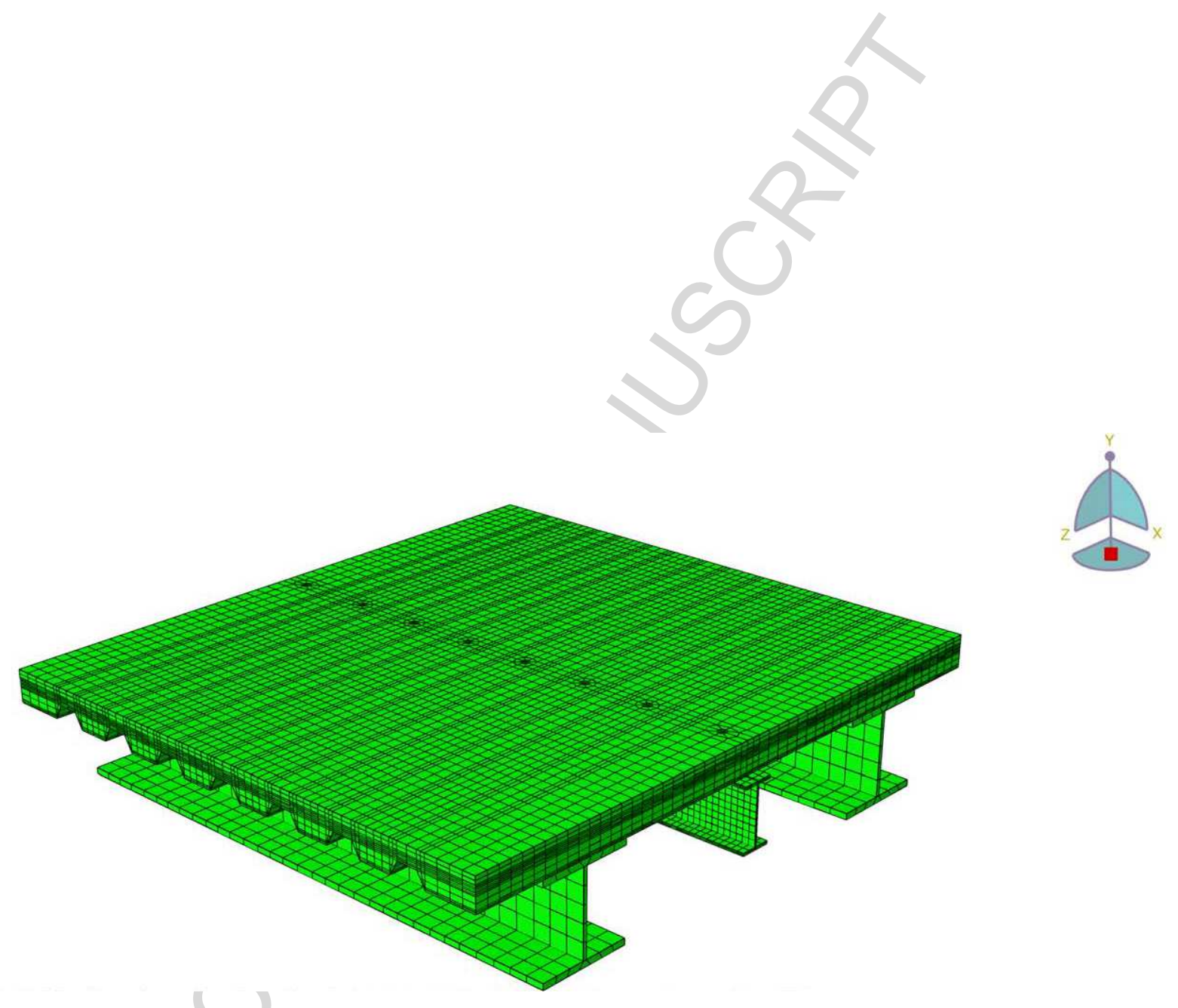

Figure 23: FE simulation: Full solid model 

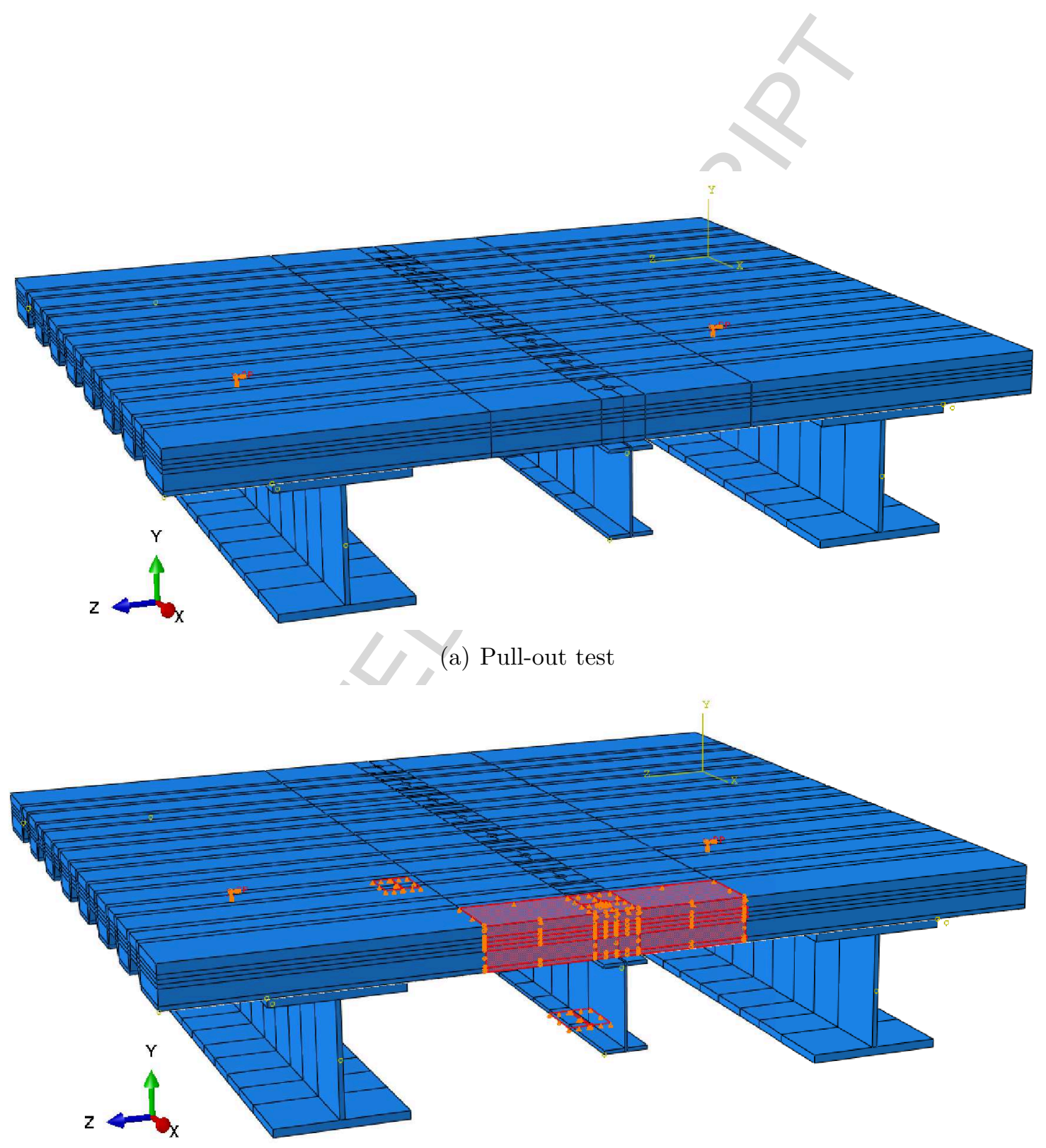

(b) Push-out test

Figure 24: Boundary conditions in the simulations 


\subsubsection{Material model}

The concrete damaged plasticity model was used for concrete material behavior. For the behavior in compression, the stress-strain relationship was used in accordance to EN 1992.1.1:

$$
\sigma_{c}=f_{c m} \frac{k \eta-\eta^{2}}{1+(k-2) \eta}
$$

in which

$$
\begin{gathered}
k=\frac{1.05 E_{c m} \varepsilon_{c 1}}{f_{c m}} \\
\eta=\frac{\varepsilon_{c}}{\varepsilon_{c 1}}
\end{gathered}
$$

where $\varepsilon_{c 1}=0.7 f_{c m}^{0.31}$ is the strain at ultimate compressive strength of concrete; $\varepsilon_{c}$ is the compressive strain in concrete; $E_{c m}$ is the secant modulus of elasticity. Following [14], the tensile behavior of the concrete was modelled by the tensile stress $\left(\sigma_{t}\right)$ versus the cracking displacement $(w)$ relationship that was defined by:

$$
\frac{\sigma_{t}}{f_{t}}=f(w)-\frac{w}{w_{c}} f\left(w_{c}\right)
$$

with

$$
\begin{gathered}
f(w)=\left[1+\left(\frac{c_{1} w}{w_{c}}\right)^{3}\right] \exp \left(-\frac{c_{2} w}{w_{c}}\right) \\
w_{c}=5.14 \frac{G_{f}}{f_{t}}
\end{gathered}
$$

where $f_{t}$ is the tentile strength, $c_{1}=3$ and $c_{2}=6.93$, for normal density concrete, are material constants, and the fracture energy $G_{f}$ is defined by [25]:

$$
G_{f}=73 f_{c m}^{0.18}
$$

For steel material model of profiled steel sheet, shear studs and rebar, an elastic perfectly plastic material behaviour is used. The modulus of elasticity of all the steel steel components is taken as $\mathrm{E}=200 \mathrm{GPa}$. The yield stress of the profiled steel sheet, shear studs and profile 
beams is assumed to be $355 \mathrm{MPa}$ while yield stress of the rebars is taken as $535 \mathrm{MPa}$.

\subsection{Parametric study}

In order to better study the effect of pre-damaging on the resistance and stiffness of the shear stud connectors, the level of the pre-damaging is varied in the numerical simulation by changing the global pull-down displacement, which was $18.75 \mathrm{~mm}$ in the experimental test (see Fig. 13). The values considered are $0,10 \mathrm{~mm}, 18.75 \mathrm{~mm}$, and $25 \mathrm{~mm}$. The first value will provide information about the initial resistance that is lacking in the experimental test.

\subsection{Results of the numerical simulations}

\subsubsection{Initial stiffness push-out test}

The initial stiffness push-out test was simulated using the beam model in ABAQUS/CAE software. Fig. 25 shows the deformed configuration of the beam model. The result obtained from the simulation is compared with the mean slip values obtained from the initial tests of specimen 1 and 3 in Fig. 26. The overall results (both the distribution and the magnitude values of the slips) are in good agreement between the numerical simulation and the experimental tests. The analytical formula in Eq. (7) includes most effects in the behavior response of shear connector based on previous experimental studies. This comparison shows that the experimental results are consistent with the classical background on the behavior of the shear connectors.

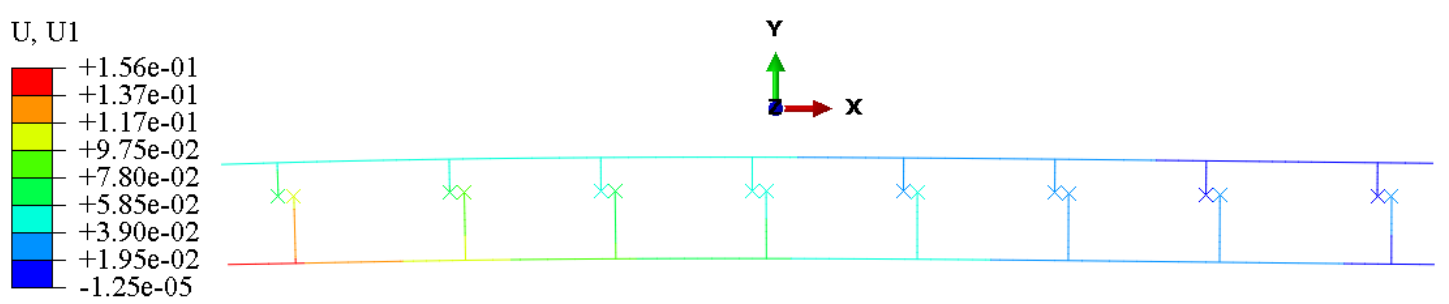

Figure 25: Simplified model: deformation (in $\mathrm{mm}$ ) 


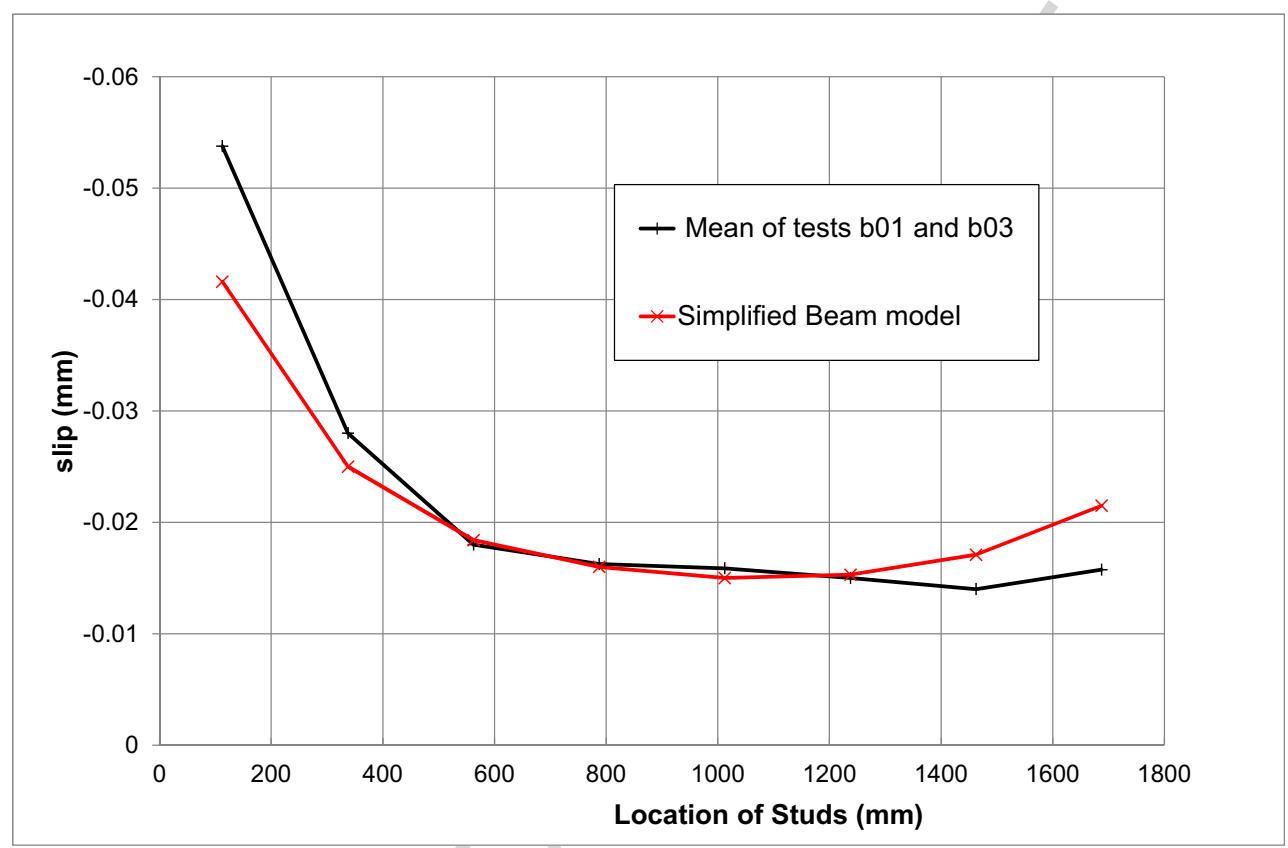

Figure 26: Initial stiffness test: Comparison of slips between experimental data and numerical simulations

\subsubsection{Pull-out test}

The pull-out test of the third specimen was also simulated using the full solid model. The force-uplift curves are compared between the experimental test and the numerical simulations (with different level of pull-out displacement) in Fig. 27. This pull-out test was intended to apply pre-damaging to the specimen in order to reproduce the explosion effect. During the experimental test, a global pull-out displacement of $18.75 \mathrm{~mm}$ was applied. The loading was stopped when the yielding of the steel sheet and rebars were assumed. With the same level of global pull-out displacement, the analysis of the stresses in the simulation confirms that the material yielding of the Comflor profiled steel sheet and rebar occurred in the flutes near the studs (see Fig. 28 and 29). Based on the stress map, the pull out force seems to develop from the head of the studs toward the web of the Comflor. This distribution of the load caused the yielding of the Comflor. This can be set in evidence by a strut 
and tie model representing the local equilibrium of the forces. From the strut and tie model with the dimensions presented in Fig. 30 and the yielding load in the Comflor, a collapse load of the stud is computed to $23 \mathrm{kN}$. This value of collapse load per stud agrees well with the one of $20 \mathrm{kN}$ from pull-out experimental test. The numerical simulation confirms the yielding of the Comflor and of the rebars, which was suspected from the observation of the force-displacement curve in experimental test. Fig. 31 shows the degree of the cone-shape damage of the concrete panel after the pull-out action.

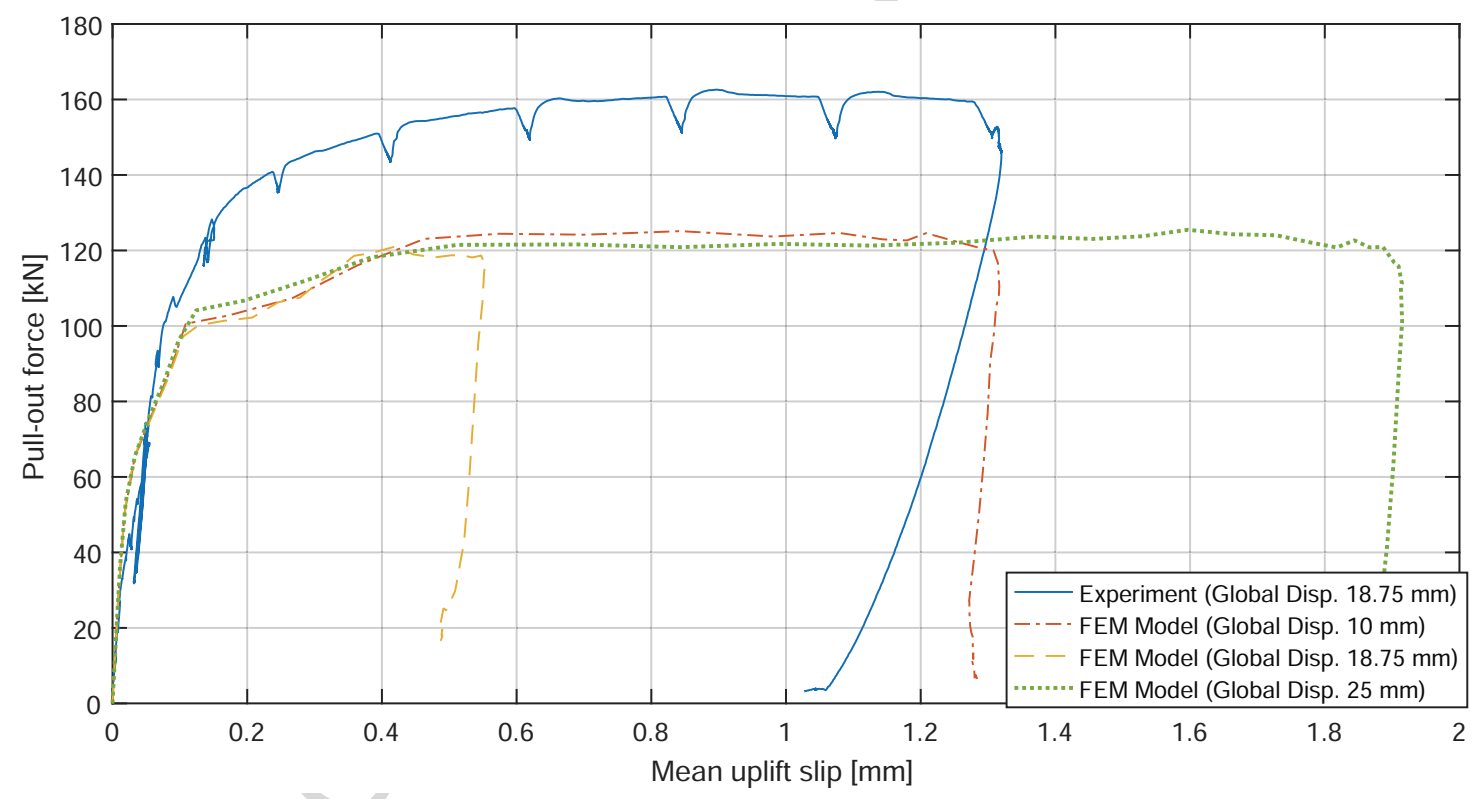

Figure 27: Pull-out test: comparison between experimental test and numerical simulation 


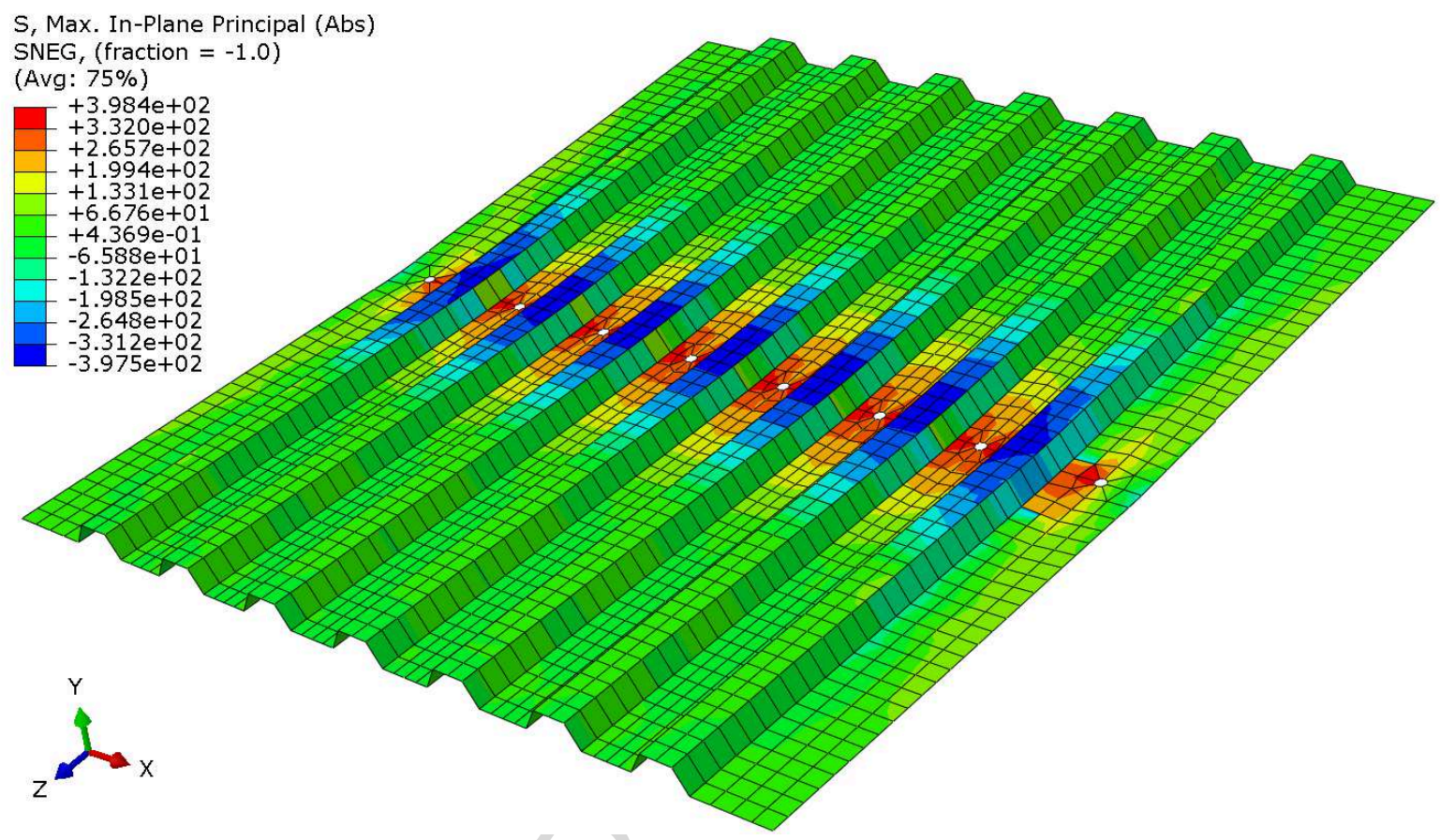

Figure 28: Stress map of profile steel sheet

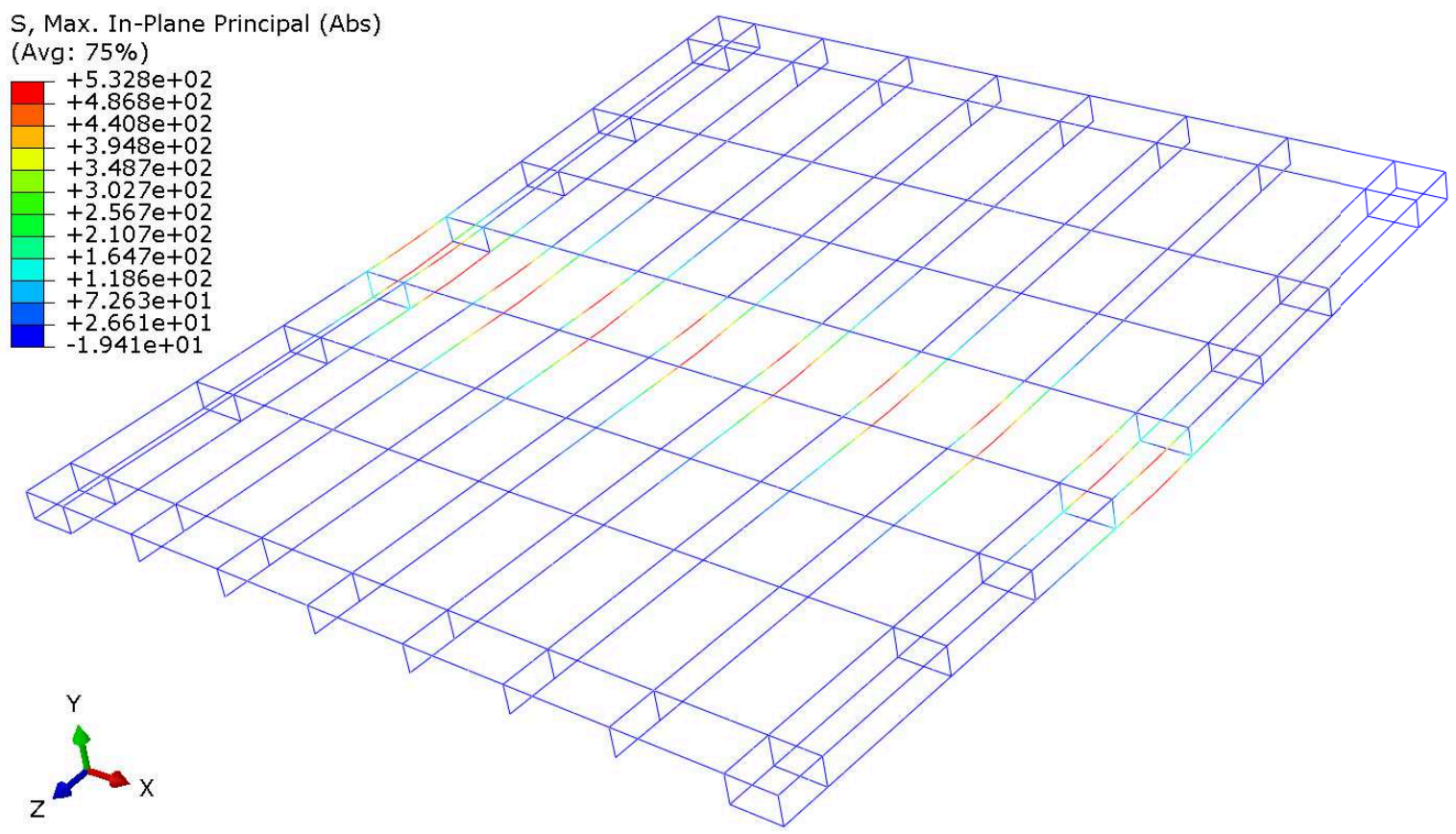

Figure 29: Stress map of rebar mesh 


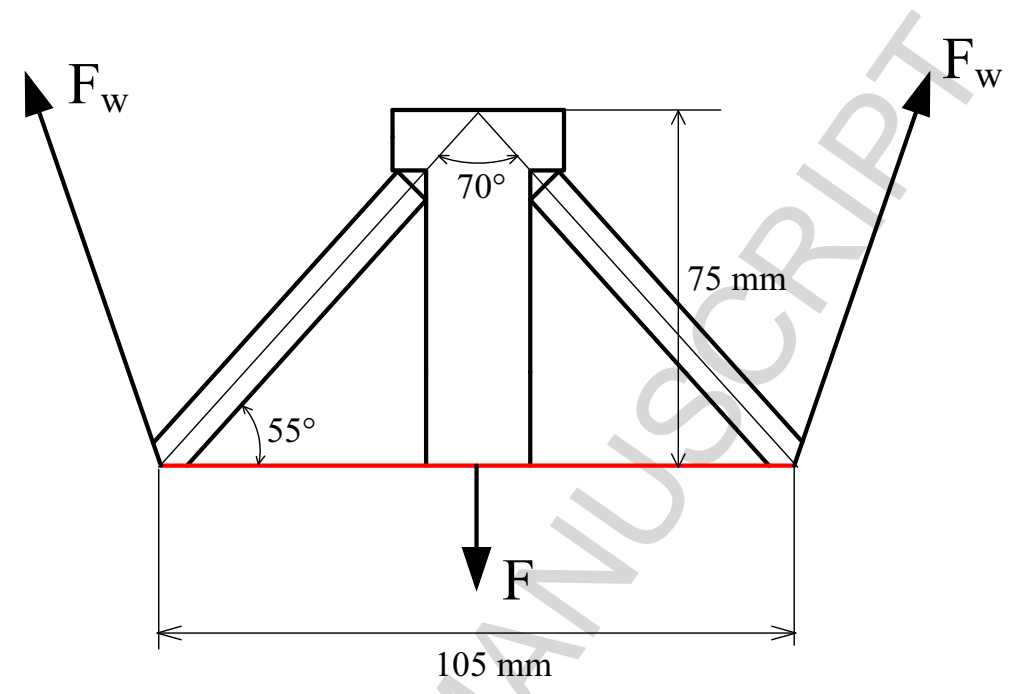

Figure 30: Strut and tie model
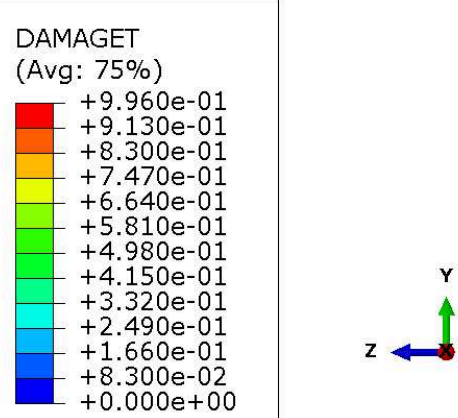

$+0.000 e+00$

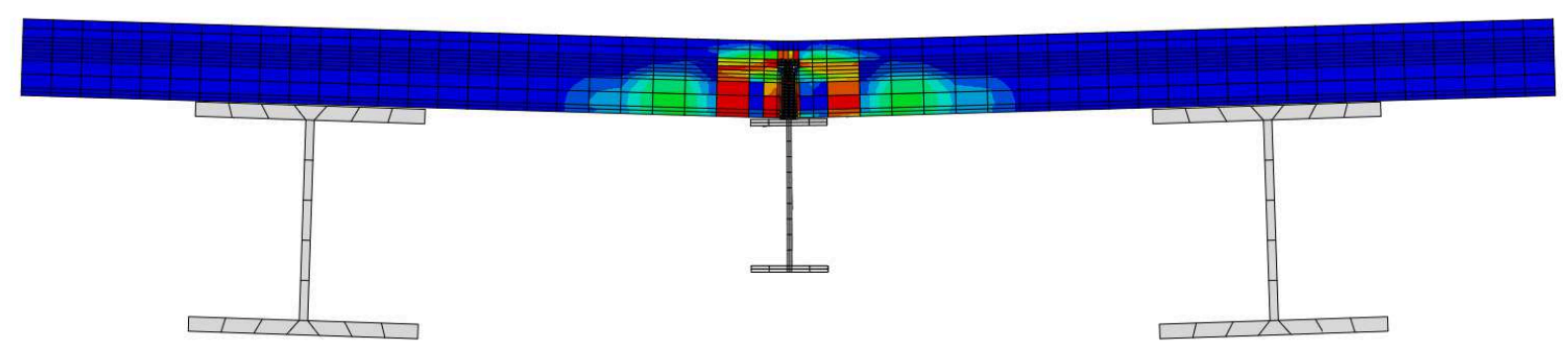

Figure 31: Tensile damage of the concrete after pull-out 


\subsubsection{Residual push-out test}

The push-out test was also simulated in a 3D model. The model was pre-damaged by the simulation of the pull-out test, and then submitted to the push-out load in order to determine the residual stiffness and resistance. The finite element modelling of the postfailure behaviour of this composite beam specimen under pull-out and push-out actions is highly complicated in account of the inelastic brittle material behaviour of concrete, the localized characteristics of shear stud connectors and the simultaneous contact interaction between various components. Various uncertainties such as contact property between the concrete panel and steel sheet also take part in the difficulty of the numerical simulation. Due to such difficulty to model the coupling effect of the damage caused by pull-out force to the shear resistance, the simulation was not able to reproduce the shear stiffness of the shear connectors in the composite specimen obtained in the experimental experiment.

In spite of that, the curves of the push-out load versus the mean slip are plotted in Fig. 32, illustrating the comparison of the results obtained from the experimental test and the FEM simulation. Considering the mentioned difficulties, it can be observed that the load-slip behaviour in the numerical simulation (with an initial global pull-out displacement $18.75 \mathrm{~mm}$ ) resembles the one obtained in the experimental test reasonably well.

The applied push-out force is distributed to the shear studs in a way that the stud closer to the applied force is under the most stress (Fig. 33). This can also be illustrated by the equivalent plastic strain in Fig. 34 .

The load-slip curves are also illustrated in Fig. 35 for different global pull-out displacements. The initial shear resistance of the shear stud connectors obtained in the simulation (zero global pull-out displacement) is $855 \mathrm{kN}$, which agrees well with the theoretically predicted initial resistance of $850 \mathrm{kN}$ (Eq. (6)). The load-slip curve makes no significant change between the case without pre-damaging and with pre-damaging of $10 \mathrm{~mm}$ global pull-out displacement. Although the steel sheet and the reinforcement bars have reached their elastic limit with the pre-damaging of applied $10 \mathrm{~mm}$ global displacement, the crack opening of the concrete panel was still insignificant that the concrete around the shear stud has not been damaged by the pull-out load of $10 \mathrm{~mm}$. On the other hand, the resisting load is 


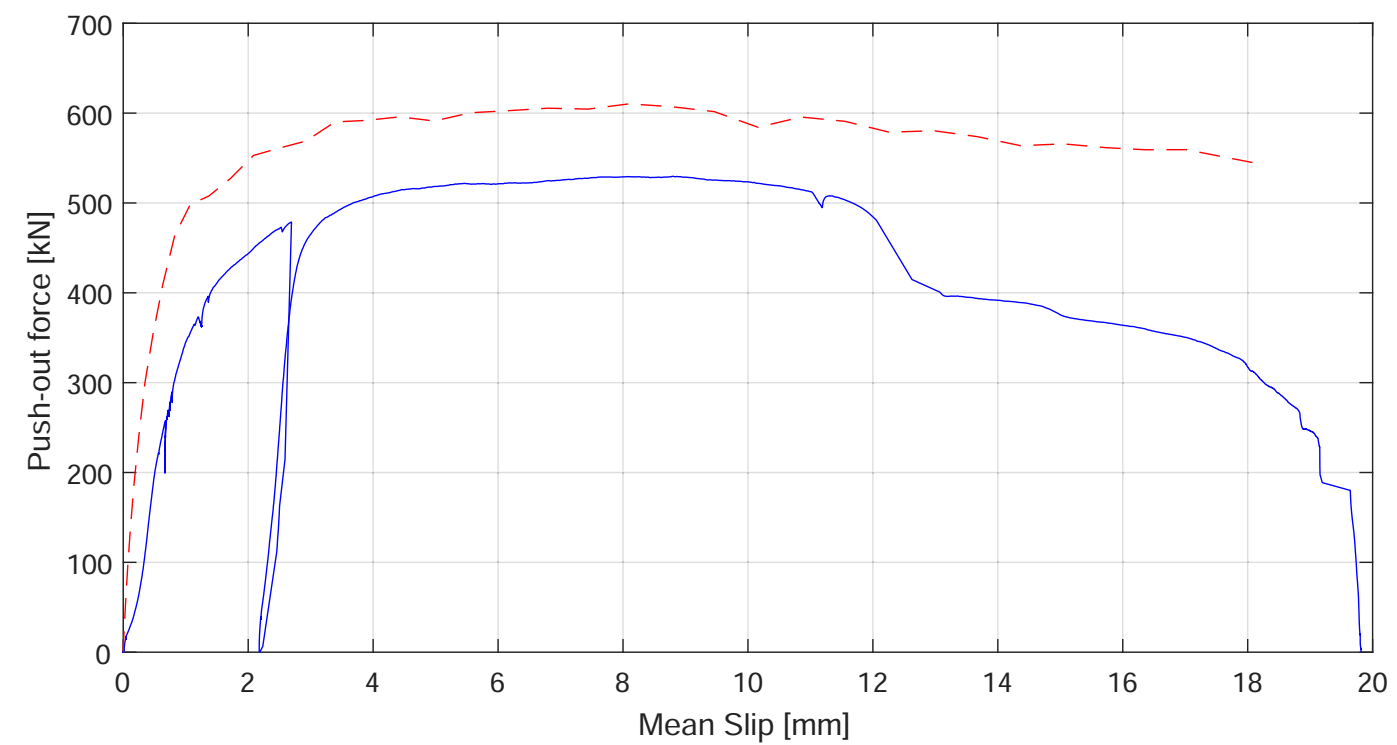

Experiment (Global Disp. 18.75 mm) - - FEM Model (Global Disp. $18.75 \mathrm{~mm}$ )

Figure 32: Comparison of residual ultimate load between experimental test and FEM simulation

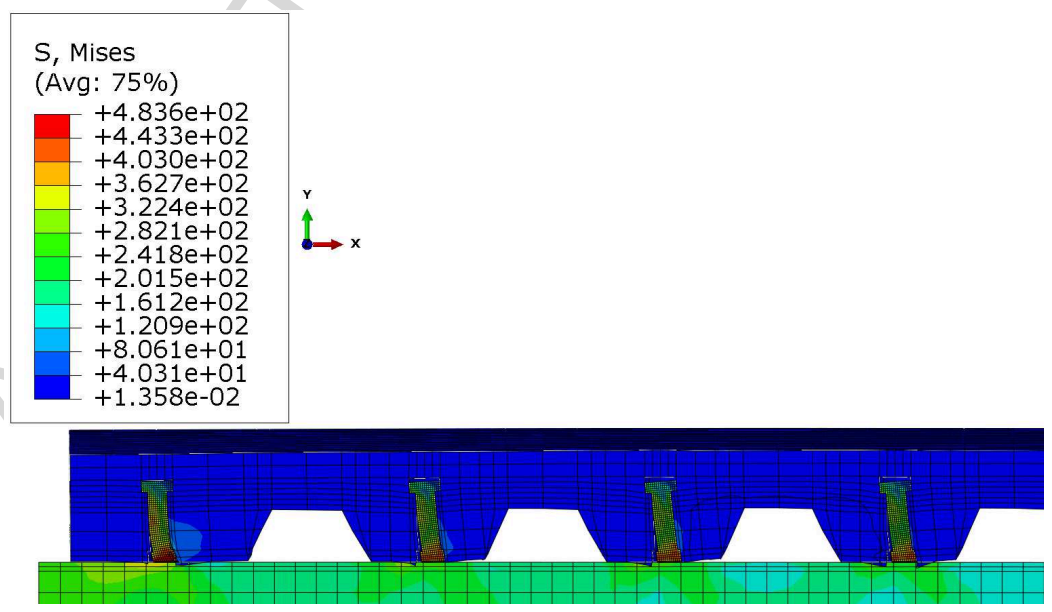

(a) Stud 1 to 4

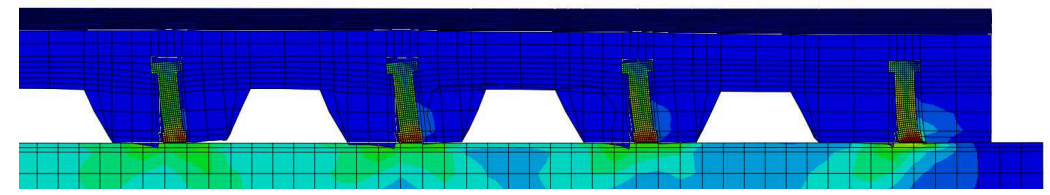

(b) Stud 5 to 6

Figure 33: stress map at the peak load of $600 \mathrm{kN}$ in final push-out 

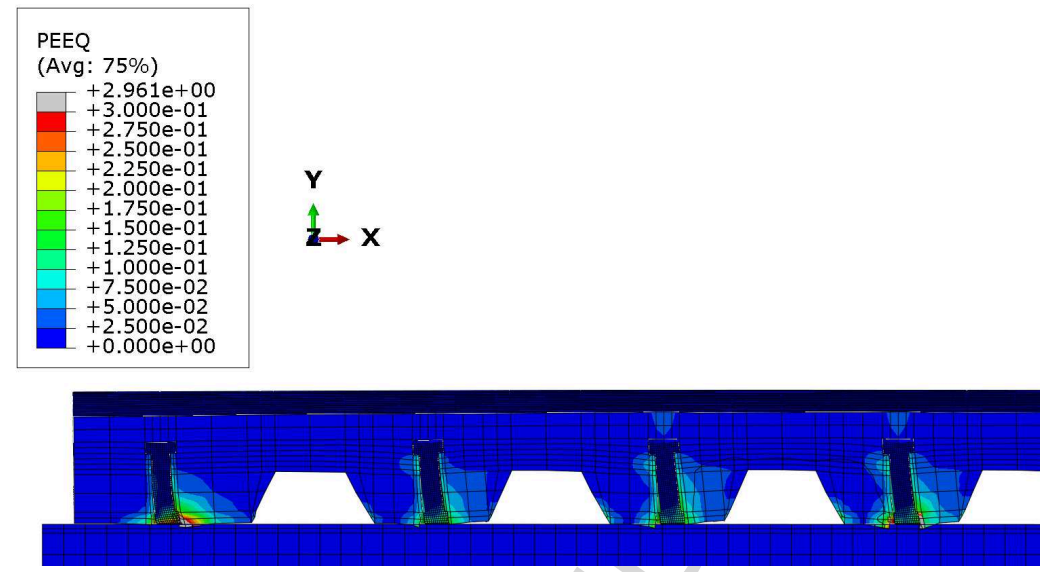

(a) Stud 1 to 4

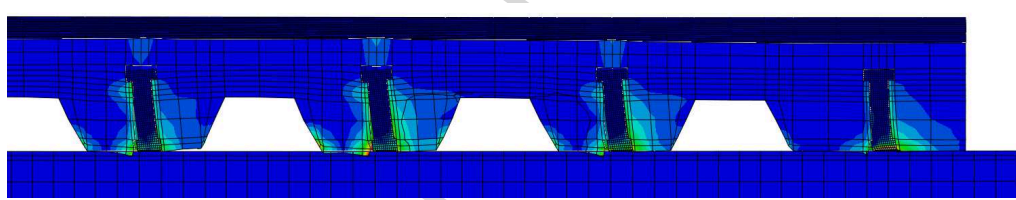

(b) Stud 5 to 6

Figure 34: Equivalent plastic strain map at the peak load of $600 \mathrm{kN}$ in final push-out

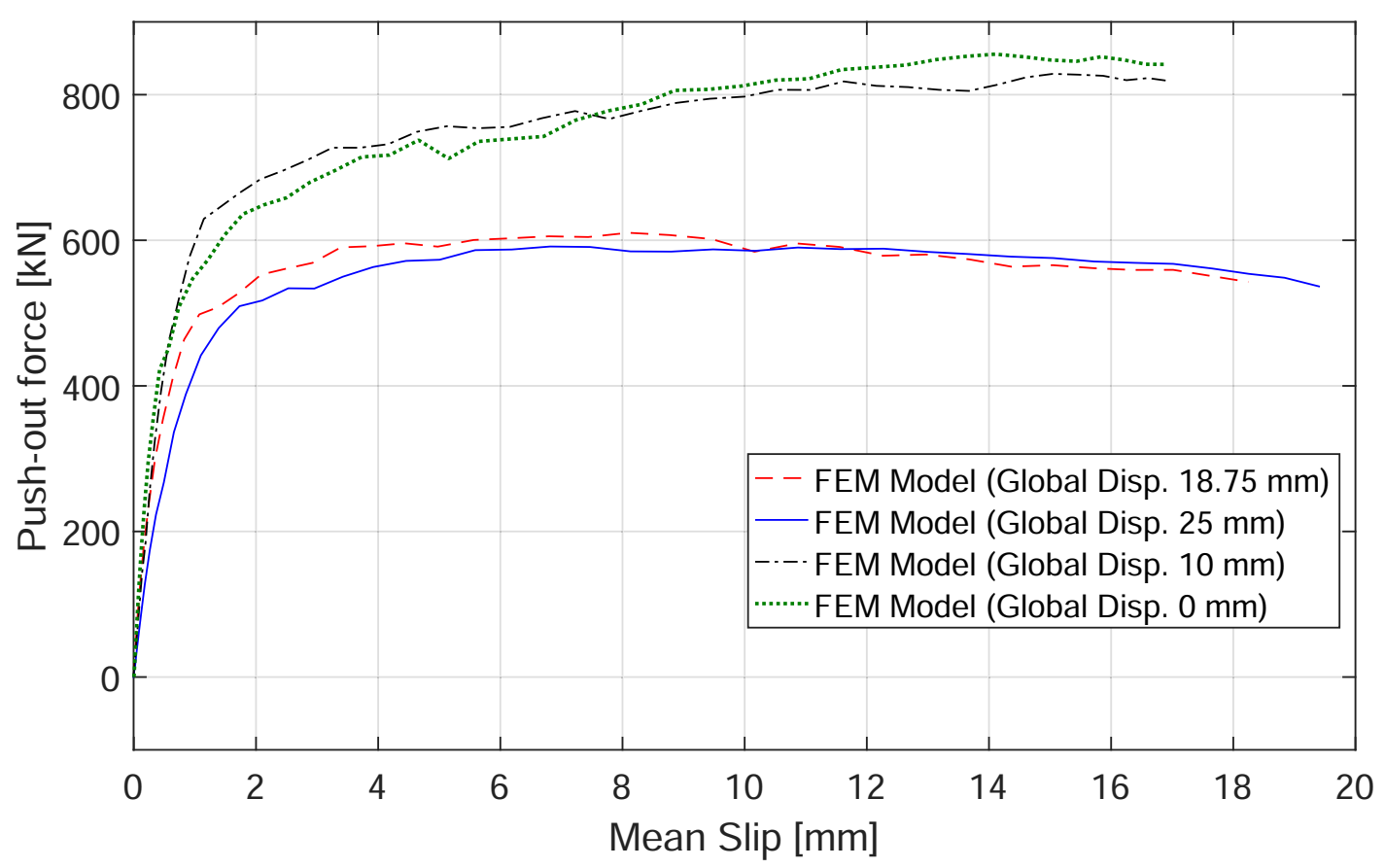

Figure 35: Comparison of residual ultimate load with different of pull-out displacements 
reduced in the case of $18.75 \mathrm{~mm}$ and $25 \mathrm{~mm}$. Besides, the load-slip curves do not differ much between the cases of $18.75 \mathrm{~mm}$ and $25 \mathrm{~mm}$ of the initial pull-out action. A general conclusion that can be drawn from this parametric study is that the ultimate shear resistance of the stud connectors is influenced by the damage of the concrete material around the shear studs. A reduction of approximately $40 \%$ of the ultimate shear resistance is obtained for the pre-damaging that leads to major concrete cracking.

\section{Conclusion}

This paper presents a series of large-scale push-out tests and pull-out tests carried out with the aim to evaluate the influence of pre-damaging on the shear capacity of headed shear stud connectors welded to steel beam and embedded in composite floor with profiled steel sheeting. Three specimens were submitted to push-out tests to determine the initial shear stiffness of the shear connectors. Next, a pull-out test was carried out on one specimen to reproduce the pre-damaging by explosion of the specimen. The pre-damaged specimen was then submitted to shear load in another push-out test to find the residual shear stiffness. Finally, the residual resistance of the specimen in shear was determined in a last push-out test that applied the shear load until full collapse of the specimen.

Two models of numerical simulation have also been performed to assess a better understanding of the experimental tests. The results from the numerical simulation provide the following insights. For one thing, experimental results of initial push-out tests are consistent with the information provided by the large historical background about the headed stud behavior under shear loading. Second, the yielding of the specimen attained in the pull-out test was confirmed and quantified.

At the end, the following information can be concluded:

- For studs in a steel-concrete connection of a composite beam that are submitted to a pull-out action that leads to the damage of the concrete around the shear studs, the residual stiffness in shear is reduced by a factor in a range between 10 and 20 compared to their initial stiffness. 
- Their residual resistance in shear is decreased by a factor of about 2 compared to their initial theoretical resistance without pre-damaging.

This preliminary study gives only partial information. However, from a practical point of view, the order of magnitude for the reduction of the initial stiffness due to pre-damaging can be considered accurate enough, bearing in mind the large uncertainties on the level of the blast actions. Regarding the resistance, it can also be inferred that the residual strength of the shear studs is sufficiently large to resist the usual wind actions as this latter induces forces that are small compared to the residual resistance.

As a conclusion, this paper gives a first full practical approach for evaluating the residual capacities of shear stud connection after being submitted to a blast action.

\section{Acknowledgements}

The authors gratefully acknowledge financial support by the European Commission (Research Fund for Coal and Steel) through the project BASIS under grant agreement RFSRCT-2013-00020.

\section{References}

[1] Kyprianou, C. Reference Building Design. Blast Actions on Structures in Steel (BASIS), RFSR-CT2013-00020, Work Package 2, Deliverable D2.1 \& D2.2, November 2013.

[2] Viest, I. M. Investigation of Stud Shear Connectors for Composite Concrete and Steel T - Beams. Journal of the American Concrete Institute, 27(8): 875 - 97, 1956.

[3] Chinn, J. Pushout Tests on Lightweight Composite Slabs. Engineering Journal, AISC, 2(4): 129 - 34, 1965.

[4] CP117. Part 1: Composite Construction in Structural Steel and Concrete. British Standard Institute, London, 1965.

[5] BS5950. Part 3.1: Structural Use of Steelwork in Building. British Standard Institute, London, 1990.

[6] EN, C. 1-1. Eurocode 4: design of composite steel and concrete structures-Part 1.1: General rules and rules for buildings. Brussels: European Committee for Standardization (2004).

[7] Ollgaard, J. G., Slutter, R. G., Fisher, J. W. Shear Strength of Stud Connectors in Lightweight and Normal Weight Concrete. Engineering Journal AISC, vol. 8, 55-64; 1971. 
[8] Prakash, A., Anandavalli, N., Madheswaran, C. K., Lakshmanan, N. Modified Push-out Tests for Determining Shear Strength and Stiffness of HSS Stud Connector-Experimental Study. International Journal of Composite Materials 2, no. 3 (2012): 22-31.

[9] Shim, C. S., Lee, P. G., Yoon, T. Y. Static Behavior of Large Stud Shear Connectors. Engineering Structures, Volume 26, Issue 12, October 2004, Pages 1853-1860.

[10] Lloyd, R.M., Wright, H.D. Shear Connection between Composite Slabs and Steel Beams. Journal of Constructional Steel Research, 15(4), pp.255-285, 1990.

[11] Smith, A. L., Couchman, G. H. Strength and Ductility of Headed Stud Shear Connectors in Profiled Steel Sheeting. Journal of Constructional Steel Research, Volume 66, Issue 6, June 2010, Pages 748-754.

[12] Hicks, S. Strength and Ductility of Headed Stud Connectors Welded in Modern Profiled Steel Sheeting. Structural Engineering International, 19(4), 415-419, 2009.

[13] Lam, D. Capacities of Headed Stud Shear Connectors in Composite Steel Beams with Precast Hollowcore Slabs. Journal of Constructional Steel Research, Volume 63, Issue 9, September 2007, Pages 1160-1174, ISSN 0143-974X.

[14] Qureshi, J., Lam, D., Ye, J. Effect of Shear Connector Spacing and Layout on the Shear Connector Capacity in Composite Beams. Journal of Constructional Steel Research, Volume 67, Issue 4, April 2011, Pages 706-719, ISSN 0143-974X

[15] ABAQUS documentation, version 6.8. USA: Hibbitt, Karlsson and Sorensen ; 2008.

[16] Pallarés, L., Hajjar, J.F. Headed Steel Stud Anchors in Composite Structures, Part II: Tension and Interaction. Journal of Constructional Steel Research, Volume 66, Issue 2, February 2010, Pages 213228, ISSN 0143-974X.

[17] Saari, W.K., Hajjar, J.F., Schultz, A.E., Shield, C.K. Behavior of Shear Studs in Steel Frames with Reinforced Concrete Infill Walls. Journal of Constructional Steel Research, 60(10), pp.1453-1480, 2004.

[18] McMakin, P. J., Slutter R. G., Fisher, J. W. Headed Steel Anchor under Combined Loading. Engineering Journal, AISC 1973, 43-52.

[19] American Institute for Steel Construction (AISC) Specification for Structural Steel Building American Institute for Steel Construction, ANSI/AISC360-05. Chicago: 2005.

[20] American Concrete Institute Committee 318 (ACI) Building Code Requirements for Structural Concrete (ACI 318-08) and Complementary (ACI 318R-08). Farmington Hills (MI): American Concrete Institute, 2008.

[21] Pre-stressed Concrete Institute (PCI) PCI Design Handbook. 6th ed. Chicago: Precast/Pre-stressed Concrete Institute, 2004.

[22] ABAQUS, Abaqus Documentation Version 6.13. 2014. Dassault Systemes: 3DS Paris Campus 10.

[23] Final report of Blast Action on Structures in Steel (BASIS), RFSR-CT-2013-00020. To be published. 
[24] Hanswille, G., Porsch, M., Ustundag, C. Resistance of headed studs subjected to fatigue loading Part II: Analytical study. Journal of constructional steel research, 63(4), pp.485-493, 2007.

[25] Richard, M., Guidelines for FE analysis of concrete dams. ENERGIFORSK, 2016. 